ARTICLE

Received 17 Mar 2015 | Accepted 1 Jun 2015 | Published 14 Jul 2015

DOI: $10.1038 /$ ncomms 8675

\title{
A novel UCS memory retrieval-extinction procedure to inhibit relapse to drug seeking
}

Yi-xiao Luo ${ }^{1,2, \star}$, Yan-xue Xue ${ }^{2, \star}$, Jian-feng Liu², ${ }^{1,}$ Hai-shui Shi ${ }^{3}$, Min Jian ${ }^{1,2}$, Ying Han ${ }^{1,2}$, Wei-li Zhu², Yan-ping Bao ${ }^{2}$, Ping Wu ${ }^{2}$, Zeng-bo Ding ${ }^{2}$, Hao-wei Shen ${ }^{2}$, Jie Shi ${ }^{2}$, Yavin Shaham ${ }^{4} \&$ Lin Lu ${ }^{1,2,5}$

We recently reported that a conditioned stimulus (CS) memory retrieval-extinction procedure decreases reinstatement of cocaine and heroin seeking in rats and heroin craving in humans. Here we show that non-contingent cocaine or methylphenidate injections (UCS retrieval) $1 \mathrm{~h}$ before the extinction sessions decreases cocaine-priming-induced reinstatement, spontaneous recovery, and renewal of cocaine seeking in rats. Unlike the CS-based memory retrieval-extinction procedure, the UCS memory retrieval manipulation decreases renewal and reinstatement of cocaine seeking in the presence of cocaine cues that were not present during extinction training and also decreases cocaine seeking when the procedure commences after 28 days of abstinence. The inhibitory effect of the UCS retrieval manipulation on cocaine-priming-induced reinstatement is mediated by regulation of AMPAreceptor endocytosis in the basolateral amygdala. The UCS memory retrieval-extinction procedure has superior relapse prevention characteristics than the CS memory retrievalextinction procedure and could be a promising method for decreasing relapse in human addicts.

\footnotetext{
${ }^{1}$ Institute of Mental Health/Peking University Sixth Hospital, Key Laboratory of Mental Health, Peking University, Beijing 100191, China. ${ }^{2}$ National Institute on Drug Dependence, Beijing Key Laboratory of Drug Dependence Research, Peking University, Beijing 100191, China. ${ }^{3}$ Department of Biochemistry and Molecular Biology, Basic Medical College, Hebei Medical University, Shijiazhuang 050017, China. ${ }^{4}$ Intramural Research Program, National Institute on Drug Abuse, National Institutes of Health, Baltimore, Maryland 21224, USA. ${ }^{5}$ Peking-Tsinghua Center for Life Sciences, PKU-IDG/McGovern Institute for Brain Research, Peking University, Beijing 100871, China. * These authors contributed equally to this work. Correspondence and requests for materials should be addressed to L.L. (email: linlu@bjmu.edu.cn).
} 
S tudies using human addicts or animal models of drug addiction indicate that conditioning factors contribute to drug addiction and that responses to drug-associated cues persist during prolonged abstinence ${ }^{1-4}$. These findings have led to the development of cue-exposure therapies to extinguish conditioned responses to drug cues 5 . However, cue-exposure therapy in the clinic often fails to prevent relapse when drug addicts return to their home environment ${ }^{6}$. The failure of the cue exposure therapy is likely because of the fact that extinguished responses to conditioned cues can be recovered by acute exposure to the unconditioned stimulus (CS, reinstatement), exposure to the original reward-associated context after extinction of the conditioned responses in a different context (renewal), or passage of time after extinction training (spontaneous recovery) $)^{7,8}$.

In recent years, investigators have used a CS memory retrievalextinction procedure to prevent recovery of fear after extinction in rats ${ }^{9,10}$ and humans ${ }^{11,12}$. In these studies, reinstatement, renewal, and spontaneous recovery of fear responding were decreased by brief exposure to cues previously paired with footshock (a retrieval manipulation) if that exposure was followed $10 \mathrm{~min}$ or $1 \mathrm{~h}$ later by repeated exposure to the same cues in longer-duration extinction sessions. We recently adapted this memory retrieval-extinction procedure to drug studies in rats (morphine, heroin, and cocaine) and humans (heroin) and found that the procedure decreases reinstatement, spontaneous recovery and renewal (context-induced reinstatement) of drug seeking in rats, and cue-induced drug craving in humans ${ }^{13}$. Our results in rats were independently replicated and extended to drug-induced reinstatement of morphine-conditioned place preference $(\mathrm{CPP})^{14,15}$ and renewal of alcohol seeking ${ }^{16}$.

However, there are limitations of the CS memory retrievalextinction procedure for 'real world' relapse prevention ${ }^{17}$. First, the inhibitory effect of the procedure is selective to the reactivated cues and does not generalize to other cues that were not reactivated $^{11,12}$. Second, inhibition of fear by this procedure only occurs when the memory retrieval-extinction manipulation is performed immediately after fear-conditioning training ${ }^{10}$. Third, for both drug self-administration and CPP, the procedure paradoxically accelerates reacquisition of the previously extinguished conditioned response ${ }^{15,16}$.

On the basis of these limitations and results demonstrating that the inhibitory effects of neuropharmacological manipulations on both fear conditioning ${ }^{18}$ and drug CPP ${ }^{19,20}$ after memory retrieval was induced by the unconditioned stimulus (UCS), we have recently developed a UCS memory retrieval-extinction procedure and demonstrated its effect on inhibition of Pavlovian conditioned fear in both rats and humans $s^{21}$. In the present study, we modified the UCS memory retrieval-extinction procedure to study its effect on reinstatement, spontaneous recovery, and renewal of cocaine seeking in an operant rat model of drug relapse $\mathrm{e}^{22}$.

We also assessed whether endocytosis of $\alpha$-amino-3-hydroxy5-methyl-isoxazole-4-propionic acid (AMPA) receptors in the basolateral amygdala (BLA), which contributes to retrieval and reconsolidation of conditioned fear ${ }^{10,23,24}$ and methamphetamine ${ }^{25}$ memories, play a role in the inhibitory effect of the UCS memory retrieval manipulation on relapse to cocaine seeking. We also chose to study AMPA receptor endocytosis in BLA because of evidence implicating AMPA receptor trafficking in the nucleus accumbens (NAc) in relapse to cocaine seeking ${ }^{26,27}$, and the role of BLA in reconsolidation of memories for cocaine cues and contexts ${ }^{28-30}$.

\section{Results}

In the experiments described below, we first trained all rats to nose poke for intravenous cocaine for $3 \mathrm{~h}$ per day for 10-14 days.
We then compared the effect of the novel UCS memory retrievalextinction procedure to our recently established CS memory retrieval-extinction procedure ${ }^{13}$ on reinstatement of cocaine seeking induced by cocaine-priming injections, spontaneous recovery of cocaine seeking after extinction, and renewal (context-induced reinstatement ${ }^{31}$ ) of cocaine seeking after extinction of cocaine self-administration in a different context. We also assessed the effect of the UCS memory retrieval-extinction procedure on reacquisition of cocaine selfadministration under a progressive ratio (PR) schedule. In the different experiments, we have used four to five experimental groups (hereafter termed Group in the statistical analyses) that were exposed to the following manipulations: saline injections $1 \mathrm{~h}$ before the extinction sessions, cocaine (3 and/or $10 \mathrm{mg} \mathrm{kg}^{-1}$; hereafter termed UCS retrieval) 1 or $9 \mathrm{~h}$ before the extinction sessions and 15-min CS retrieval $1 \mathrm{~h}$ before the extinction sessions. During the 3-h extinction sessions, active nose-poke responding led to contingent presentations of a tone-light cue previously paired with cocaine injections during training, but cocaine was not delivered. The CS retrieval manipulation was a short 15-min session during which the experimental conditions were identical to those of the extinction sessions ${ }^{13}$. The experimental groups used in each experiment are described in the Methods section and the figures.

The delayed 9-h group (cocaine injections $9 \mathrm{~h}$ before the extinction sessions), a standard control condition in studies on memory consolidation ${ }^{32}$ and reconsolidation ${ }^{33-35}$, served as a control condition for the temporal specificity of the UCS memory retrieval-extinction manipulation. We have not included this temporal control condition for the CS retrieval manipulation because we previously found that this manipulation had no effect on cocaine or heroin seeking when it was presented $6 \mathrm{~h}$ before the extinction sessions ${ }^{13}$.

Effect on reinstatement of drug seeking. In Experiment 1, we tested the inhibitory effect of the UCS and CS memory retrievalextinction procedures on cocaine-priming-induced reinstatement (Supplementary Fig. 1). The statistical analysis included the between-subjects factor of Group and the within-subjects factor of Cocaine priming $\left(0,5,10\right.$ and $\left.15 \mathrm{mg} \mathrm{kg}^{-1}\right)$. We found that exposing rats to the UCS and CS retrieval manipulations $1 \mathrm{~h}$ before the extinction sessions decreased cocaine-priming-induced reinstatement of cocaine seeking $\left(F_{(12,132)}=11.1, P<0.01\right.$ for Group $\times$ Cocaine Priming interaction). No group differences were found for responding on the inactive nose-poke operandum $(P$ values $>0.1)$. In addition, both the UCS and CS memory retrieval-extinction manipulations accelerated extinction responding $\quad\left(F_{(52,572)}=1.8, \quad P<0.01 \quad\right.$ for $\quad$ Group $\times$ Extinction Session).

In Experiment 2, we tested the inhibitory effect of the UCS and CS memory retrieval-extinction procedures on spontaneous recovery of cocaine seeking (Supplementary Fig. 2). The statistical analysis included the between-subjects factor of Group and the within-subjects factor of Test session (immediate extinction session, delay 28 day extinction session). We found that exposing rats to the UCS and CS retrieval manipulations $1 \mathrm{~h}$ before the extinction sessions decreased spontaneous recovery of cocaine seeking $\left(F_{(3,36)}=14.5, P<0.01\right.$ for Group $\times$ Test session interaction). No group differences were found for responding on the inactive nose-poke operandum ( $P$ values $>0.1)$. In addition, both the UCS and CS memory retrieval-extinction manipulations accelerated extinction responding $\left(F_{(39,468)}=2.0, P<0.01\right.$ for Group $\times$ Extinction Session). We also assessed whether the inhibitory effect of the UCS and CS retrieval manipulations on relapse to cocaine seeking is associated with decreased neuronal 
activation (c-Fos expression ${ }^{36}$ ) in medial prefrontal cortex, NAc, and amygdala. Neuronal activity in these brain areas is involved in relapse to drug seeking ${ }^{37-39}$ and conditioned drug effects ${ }^{40}$. We found that both the UCS and CS retrieval manipulations decreased c-Fos expression in the anterior cingulate cortex (ACC), BLA, and NAc core and shell induced by the spontaneous recovery test 28 days after the last extinction session $\left(F_{(3,23)}=13.7,9.2,5.2\right.$ and $7.3, P$ values $<0.01$, for the different brain areas, respectively; Supplementary Fig. 3). In contrast, no group differences in c-Fos expression were found in the central amygdala (CeA), prelimbic (PrL) and infralimbic (IL) medial prefrontal cortex ( $P$ values $>0.1$; Supplementary Fig. 4).

In Experiment 3, we tested the inhibitory effect of the UCS and CS memory retrieval-extinction procedures on renewal (contextinduced reinstatement) of cocaine seeking (Supplementary Fig. 5). The statistical analysis included the between-subjects factor of Group and the within-subjects factor of Context (last extinction session in context $\mathrm{B}$, test session in context $\mathrm{A}$ ). We found that exposing rats to the UCS and CS retrieval manipulations $1 \mathrm{~h}$ before the extinction sessions decreased renewal of cocaine seeking $\left(F_{(3,35)}=4.2, P<0.05\right.$ for Group $\times$ Context interaction). No group differences were found for responding on the inactive nose-poke operandum ( $P$ values $>0.1$ ). Additionally, both the UCS and CS memory retrieval-extinction manipulations accelerated extinction responding $\left(F_{(36,420)}=1.9\right.$, $P<0.01$ for Group $\times$ Extinction Session). We also found that both the UCS and CS retrieval manipulations decreased c-Fos expression in the ACC, BLA, and NAc core and shell induced by the renewal test $24 \mathrm{~h}$ after the last extinction session $\left(F_{(3,23)}=9.0\right.$, $11.2,4.6$ and $8.2, P$ values $<0.01$, for the different brain areas, respectively, Supplementary Fig. 6). In contrast, no group differences in c-Fos expression were found in CeA, PrL and IL ( $P$ values $>0.1$, Supplementary Fig. 7).

Effect on reacquisition of cocaine self-administration. As mentioned in the Introduction, the CS memory retrievalextinction procedure paradoxically accelerates reacquisition of the previously extinguished conditioned response for both alcohol self-administration and morphine $\mathrm{CPP}^{15,16}$. Therefore, in Experiment 4 we tested the effect of the UCS and CS memory retrieval-extinction procedures on reacquisition of cocaine seeking under a PR reinforcement schedule (Supplementary Fig. 8). We chose to assess reacquisition using a PR reinforcement schedule instead of the fixed ratio 1 (FR1) reinforcement schedule we used during self-administration training because the PR reinforcement schedule is thought to provide a more direct measure of the rewarding effects of a drug than continuous reinforcement schedules ${ }^{41}$.

The statistical analysis included the between-subjects factor of Group and the within-subjects factor of Day (the three reacquisition days). We found that exposing rats to the UCS retrieval manipulation (and, to a lesser degree, the CS retrieval manipulation) $1 \mathrm{~h}$ before the extinction sessions decreased reacquisition of cocaine self-administration. The statistical analyses showed a main effect of Group for latency to first respond in the first reacquisition session $\left(F_{(3,34)}=4.9, P<0.05\right)$, final ratio on the PR schedule $\left.F_{(3,31)}=15.9, P<0.01\right)$ and total active nose pokes $F(3,31)=11.3, P<0.01)$, but not inactive nose pokes $(P>0.05)$. Finally, unlike the results of the previous experiments, the UCS and CS memory retrieval-extinction manipulations did not accelerate extinction responding $(P>0.1$ for Group $\times$ Extinction Session).

Effect on relapse induced by a non-extinguished cocaine cue. In Experiment 5 we assessed whether the inhibitory effect of the
UCS and CS memory retrieval-extinction procedures on renewal (context-induced reinstatement) and cocaine-priming-induced reinstatement is also observed when, during the relapse tests, extinguished operant nose-poke responding leads to contingent delivery of a discrete CS cue that had not been previously extinguished during the extinction phase (Fig. 1). As shown in Fig. 1a, we first trained the rats to self-administer cocaine in contexts $\mathrm{A}^{\prime}$ and $\mathrm{B}^{\prime}$ where nose pokes for cocaine were paired with CS1 (continuous tone-light cue) or CS2 (intermittent tone-light cue), respectively. Next, we exposed different groups of rats to the UCS and CS retrieval manipulations (both CS1 and CS2 were retrieved in the $\mathrm{CS}$ retrieval manipulation) in context $\mathrm{B}^{\prime}$ before extinction sessions during which nose pokes led to contingent delivery of CS2. Next, we tested the rats in consecutive sessions for renewal in context $\mathrm{A}^{\prime}$, saline priming in context $\mathrm{B}^{\prime}$ (baseline vehicle condition) and cocaine priming in contexts $\mathrm{A}^{\prime}$ and $\mathrm{B}^{\prime}$ (Fig. 1a).

The main finding in Experiment 5 was that the inhibitory effect of the UCS memory retrieval-extinction manipulation on renewal and cocaine-priming-induced reinstatement was observed for both the extinguished CS (CS2) and the non-extinguished CS (CS1). In contrast, the inhibitory effect of the CS memory retrieval-extinction manipulation was selective to cocaine priming in the presence of the extinguished CS2 in context $\mathrm{B}^{\prime}$; the CS memory retrieval-extinction manipulation had no effect on either renewal or cocaine-priming-induced reinstatement in context $\mathrm{A}^{\prime}$ in which nose-poke responding led to contingent delivery of the non-extinguished CS1 during testing (Fig. 1c).

The statistical analysis of nose-poke responding during the renewal test showed a significant effect of Group $\left(F_{(3,27)}=15.8\right.$, $P<0.01)$. The analysis of nose-poke responding during the cocaine-priming test in context $\mathrm{B}^{\prime}$ showed a significant Group $\times$ Cocaine priming (saline, $\left.10 \mathrm{mg} \mathrm{kg}^{-1}\right)$ interaction $\left(F_{(3,27)}=21.5\right.$, $P<0.01)$. The statistical analysis of nose-poke responding during the cocaine-priming test in Context $\mathrm{A}^{\prime}$ showed a significant effect of Group $\left(F_{(3,27)}=24.6, P<0.01\right)$. No group differences were found for responding on the inactive nose-poke operandum in the different tests $(P$ values $>0.1)$. In addition, both the UCS and CS memory retrieval-extinction manipulations accelerated extinction responding $\left(F_{(33,297)}=3.5, P<0.01\right.$, Fig. 1b).

Effect on relapse to cocaine seeking after prolonged abstinence. Fear-conditioning studies indicate that the inhibitory effect of the CS memory retrieval-extinction procedure on fear inhibition is time-dependent: the procedure is effective when performed immediately after fear-conditioning training but not when it is performed after a delay period between training and the CS retrieval-extinction exposure ${ }^{10}$. On the basis of this finding, in Experiments 6-8 we assessed the effect of the UCS and CS memory retrieval-extinction procedures on reinstatement (cocaine priming), spontaneous recovery, and renewal of cocaine seeking after imposing a 28-day withdrawal (abstinence) period between cocaine self-administration training and the start of the retrieval-extinction procedures. The main finding was that after this withdrawal period, the UCS memory retrieval-extinction manipulation maintained its ability to decrease reinstatement (cocaine priming), spontaneous recovery, and renewal of cocaine seeking, while the CS memory retrieval-extinction manipulation did not (Figs 2-4).

In Experiment 6 (Fig. 2), we found that exposing rats to the UCS but not the CS retrieval-extinction manipulation $1 \mathrm{~h}$ before the extinction sessions decreased cocaine-priming-induced reinstatement of cocaine seeking $\left(F_{(3,30)}=8.9, \quad P<0.01\right.$ for Group $\times$ Cocaine priming $[0,10 \mathrm{mg} / \mathrm{kg}]$ interaction). No group differences were found for responding on the inactive nose-poke 
operandum ( $P$ values $>0.1)$. In addition, the UCS but not the CS memory retrieval-extinction manipulations accelerated extinction responding $\quad\left(F_{(39,390)}=1.5, \quad P<0.05\right.$ for Group $\times$ Extinction session).

In Experiment 7 (Fig. 3), we found that exposing rats to the UCS but not to the CS retrieval-extinction manipulations $1 \mathrm{~h}$ before the extinction sessions decreased spontaneous recovery of cocaine seeking $\left(F_{(3,40)}=13.9, P<0.01\right.$ for Group $\times$ Test session (immediate extinction session, delay 28-day extinction session) interaction). No group differences were found for responding on the inactive nose-poke operandum $(P$ values $>0.1)$. In addition, the UCS but not the CS memory retrieval-extinction manipulations accelerated extinction responding $\left(F_{(39,532)}=4.0, P<0.01\right.$ for Group $\times$ Extinction session).

In Experiment 8 (Fig. 4), we found that exposing rats to the UCS but not the CS retrieval-extinction manipulations $1 \mathrm{~h}$ before the extinction sessions decreased renewal of cocaine seeking $\left(F_{(3,41)}=8.0, \quad P<0.01\right.$ for Group $\times$ Context (last extinction session in context $B$, test session in context $A$ ) interaction). No group differences were found for responding on the inactive nose-poke operandum ( $P$ values $>0.1)$. In addition, the UCS but not the CS memory retrieval-extinction manipulations, accelerated extinction responding $\left(F_{(33,451)}=4.2, P<0.01\right.$ for Group $\times$ Extinction session).

No effect of reversing the UCS retrieval-extinction sequence. In a recent study, Millan et al. ${ }^{16}$ trained rats to self-administer alcoholic beer and reported that a short CS memory retrieval (10 min of lever presses that led to contingent presentations of the alcohol-associated discrete cues) that was followed $70 \mathrm{~min}$ later by 50 min extinction sessions under the same experimental conditions, decreased renewal (context-induced reinstatement) of alcohol seeking. However, these authors also reported that reversing the experimental sequence (50-min extinction followed 70 min later by $10-$ min CS retrieval) had the same effect on renewal of alcohol seeking. On the basis of these findings, in Experiment 9 we assessed whether reversing the extinction and the UCS retrieval conditions would affect renewal of cocaine seeking. We found that reversal of the experimental conditions

a

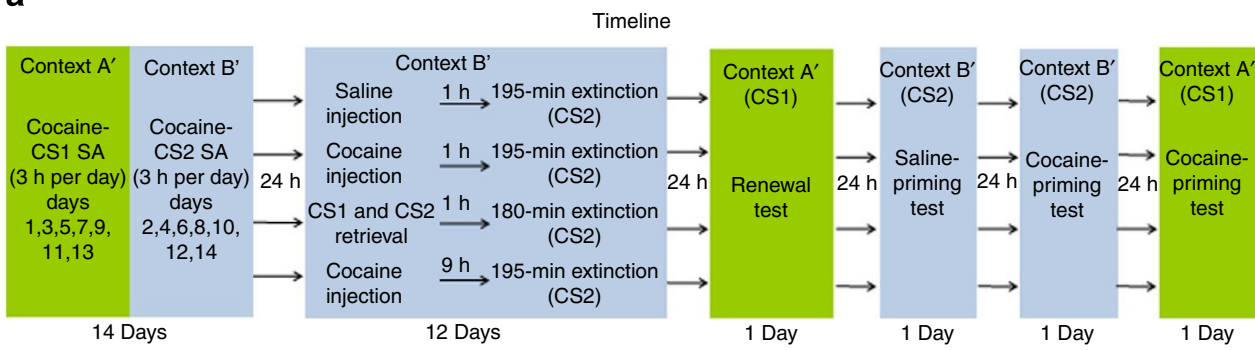

b
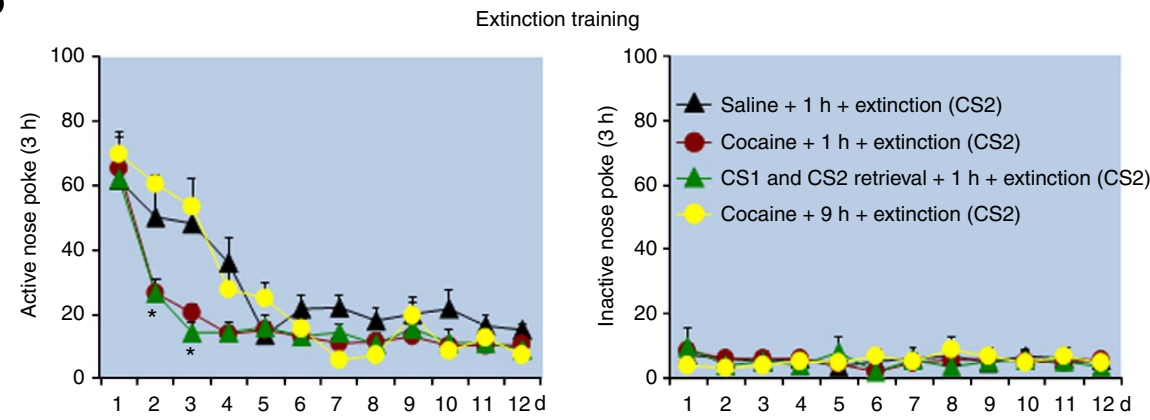

C
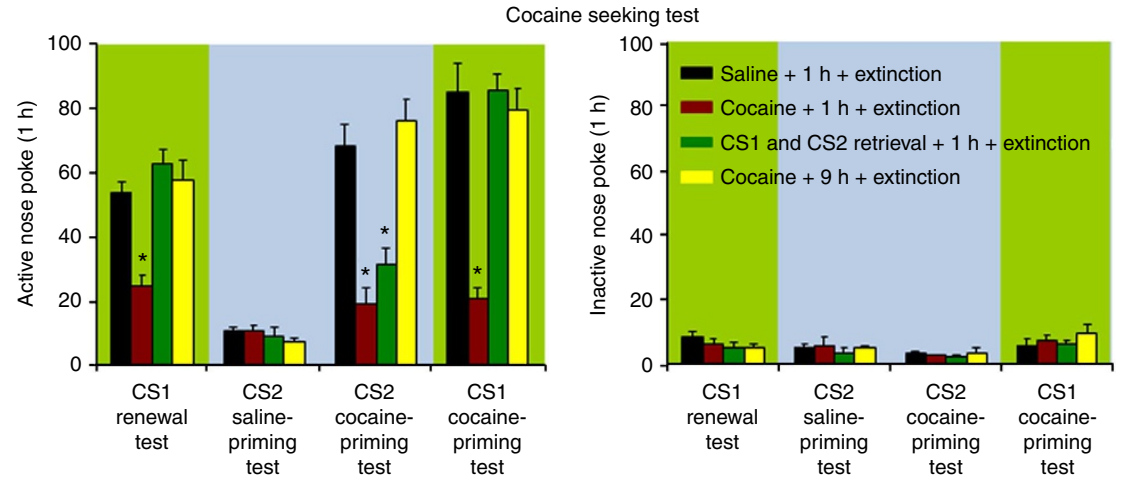

Figure 1 | Exposure to the UCS but not the CS memory retrieval-extinction manipulation decreased renewal and cocaine-priming-induced reinstatement when nose-poke responding during testing was reinforced by a non-extinguished discrete CS. (a) Timeline of the experimental procedure. $(\mathbf{b}, \mathbf{c})$ The mean number of responses on the active and inactive nose-poke devices during the extinction phase and reinstatement tests. ${ }^{\star}$ Different from 'saline $+1 \mathrm{~h}+$ extinction', mixed ANOVA, ${ }^{\star} P<0.05 ; n=7-8$ per experimental condition. Error bars represent s.e.m. See Methods and Results for details of the experimental procedure. 
had no effect on renewal of cocaine seeking (Supplementary Fig. 9). The statistical analysis of active nose-poke responding included the between-subjects factor of Group and the withinsubjects factor of Context (last extinction session in context $\mathrm{B}$, test session in context A). This analysis showed a significant effect of Context $\left(F_{(1,15)}=141.1, P<0.01\right)$ but no significant effects of Group or Group $\times$ Context interaction. No group differences were found for responding on the inactive nose-poke operandum $(P$ values $>0.1)$. In addition, the reversal manipulation had no effect on extinction responding ( $P$ values $>0.1)$.

Effect of inhibition of AMPAR endocytosis in BLA. In Experiments 10-11, we assessed whether endocytosis of AMPA receptors in BLA, which contributes to retrieval and reconsolidation of conditioned fear ${ }^{10,23,24}$ and methamphetamine ${ }^{25}$ memories, plays a role in the inhibitory effect of the UCS memory retrieval manipulation on relapse to cocaine seeking. As mentioned in the Introduction, we also chose to study AMPA receptor endocytosis in BLA because of evidence implicating AMPA receptor trafficking in the NAc in relapse to cocaine seeking ${ }^{26,27}$, and the role of BLA in reconsolidation of memories for cocaine cues and contexts ${ }^{28-30}$.

In Experiment 10 (Fig. 5a), we assessed the effect of UCS retrieval on the membrane expression of GluA1 and GluA2 in
BLA. The statistical analysis included the between-subjects factor of Group. We found that membrane levels of GluA1 $\left(F_{(2,17)}=20.1, P<0.01\right)$ and GluA2 $\left(F_{(2,17)}=15.0, P<0.01\right)$ were decreased $1 \mathrm{~h}$ after UCS (non-contingent cocaine) exposure (Fig. 5b and Supplementary Fig. 10).

In Experiment 11 we assessed whether blockade of endocytosis of AMPAR in BLA would reverse the effect of the UCS memory retrieval-extinction procedure on cocaine-priming-induced reinstatement. For this purpose, we used the GluA2 3 peptide, which has been shown in several studies to inhibit GluA2dependent AMPAR endocytosis ${ }^{42-44}$. We found that injections of GluA2 $2_{3 y}$ into BLA blocked the inhibitory effect of UCS memory retrieval-extinction manipulation on cocaine-priming-induced reinstatement (Fig. 6a; see Supplementary Fig. 11 for the anatomical placement of the intracranial injectors). The statistical analysis, which included the between-subjects factors of UCS Manipulation (saline, cocaine $\left.\left(3 \mathrm{mg} \mathrm{kg}^{-1}\right)\right)$ and GluA2 $3 \mathrm{y}$ Condition (scramble peptide, GluA2 ${ }_{3 y}$ ), and the within-subjects factor of Cocaine priming $\left(0,10 \mathrm{mg} \mathrm{kg}^{-1}\right)$, showed a significant interaction between the three factors $\left(F_{(1,37)}=15.0, P<0.01\right.$, Fig. 6c). No group differences were found for responding on the inactive nose-poke operandum ( $P$ values $>0.1$ ). In addition, BLA injections of GluA2 $3 y$ blocked the accelerating effect of UCS memory retrieval-extinction manipulation on extinction

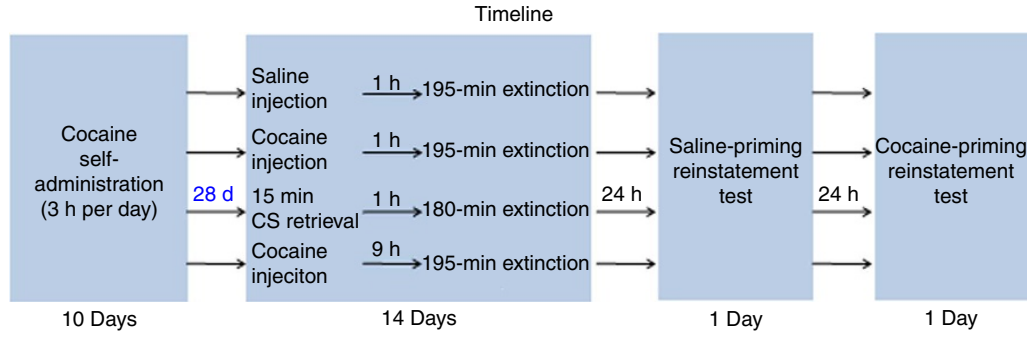

b
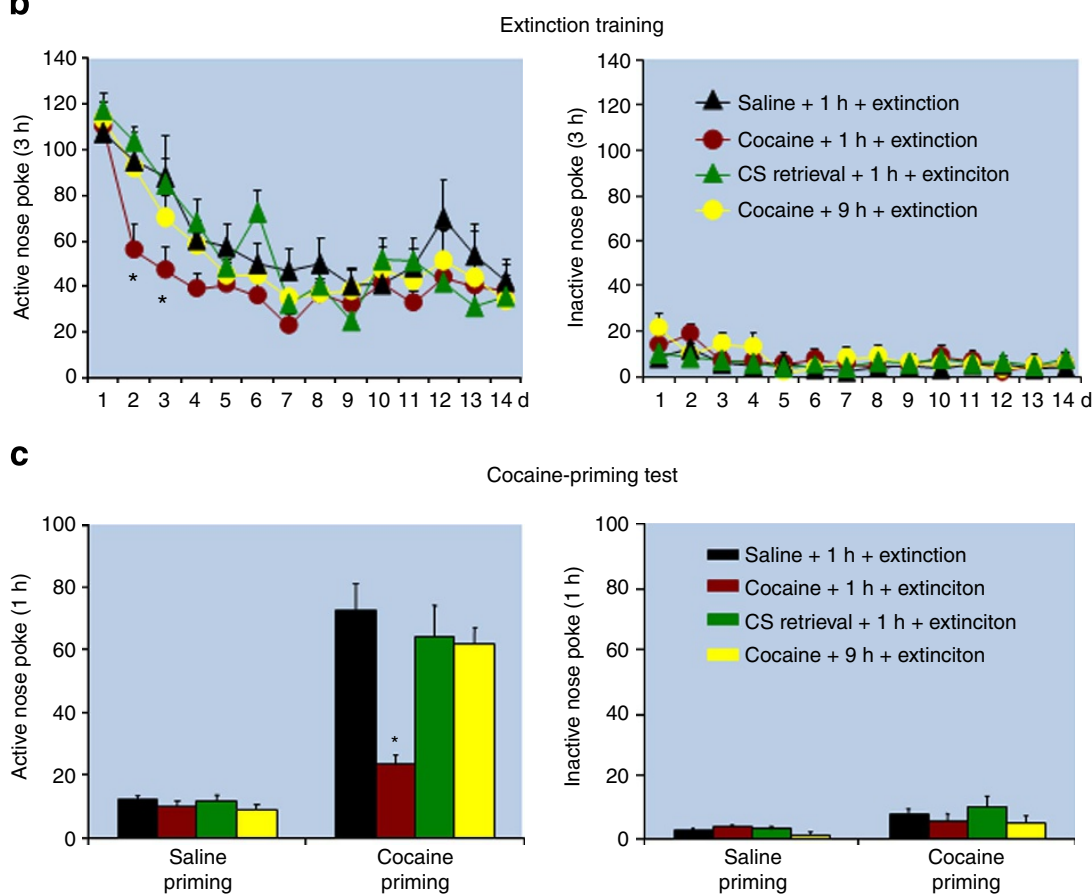

Figure 2 | Exposure to the UCS but not the CS memory retrieval-extinction manipulation 28 days after cocaine self-administration training accelerated extinction responding and decreased cocaine-priming-induced reinstatement of drug seeking. (a) Timeline of the experimental procedure.

$(\mathbf{b}, \mathbf{c})$ The mean number of responses on the active and inactive nose-poke devices during the extinction phase and reinstatement tests. ${ }^{*}$ Different from 'saline $+1 \mathrm{~h}+$ extinction', mixed ANOVA, ${ }^{\star} P<0.05 ; n=8-9$ per experimental condition. Error bars represent s.e.m. 


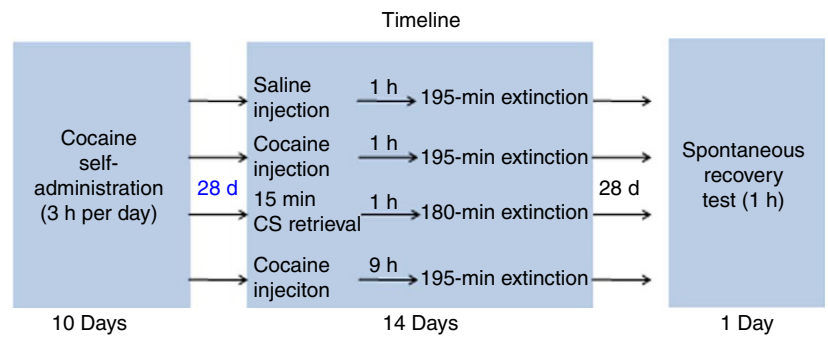

b
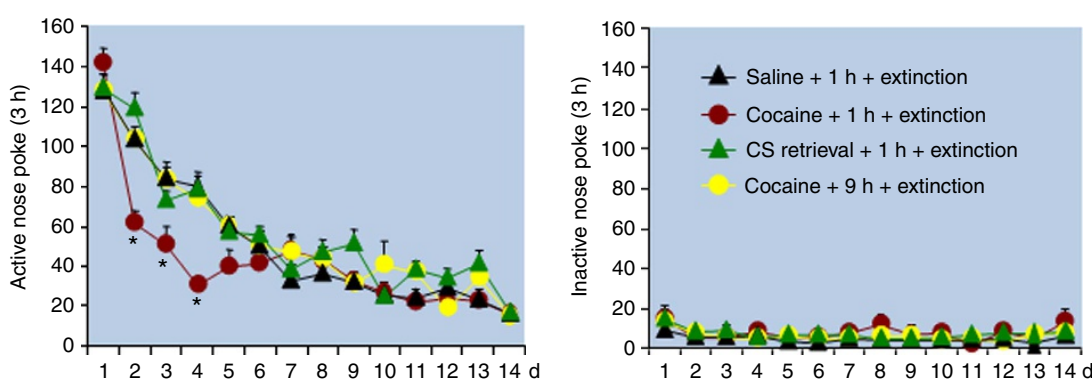

C

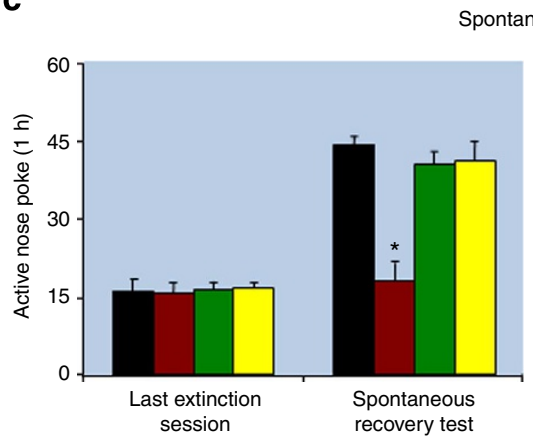

Spontaneous recovery test

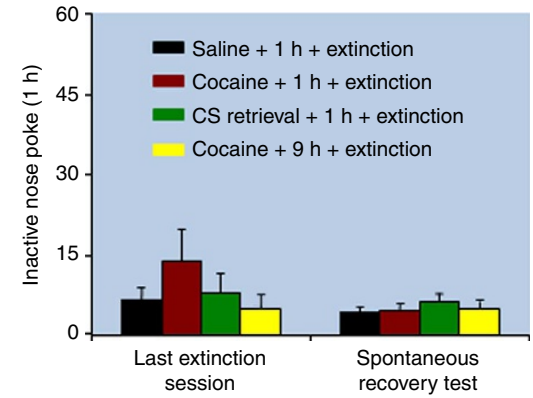

Figure 3 | Exposure to the UCS but not the CS memory retrieval-extinction manipulation 28 days after cocaine self-administration training accelerated extinction responding and decreased spontaneous recovery of cocaine seeking. (a) Timeline of the experimental procedure. (b,c) The mean number of responses on the active and inactive nose-poke devices during the extinction phase and spontaneous recovery test. *Different from 'saline $+1 \mathrm{~h}+$ extinction', mixed ANOVA, ${ }^{\star} P<0.05 ; n=11-12$ per experimental condition. Error bars represent s.e.m.

responding $\left(F_{(13,481)}=3.3, P<0.01\right.$ for UCS Manipulation $\times$ GluA2 $2_{3 y}$ Condition $\times$ Extinction Session interaction, Fig. 6b).

Effect of UCS memory retrieval by methylphenidate. Our data indicate that the UCS retrieval procedure using cocaine as the UCS inhibits relapse to cocaine seeking under a wide range of experimental conditions. However, from a treatment perspective, it is highly likely that both clinicians and regulatory agencies would be reluctant to expose cocaine addicts to their abused drug in the clinic. Therefore, in Experiments 12-13 we used four groups of rats to determine the generality of the UCS retrieval manipulation to methylphenidate, an FDA-approved medication. Methylphenidate is a central nervous system stimulant that has been widely used in the treatment of attention deficit hyperactivity disorder ${ }^{45}$. Similar to cocaine, methylphenidate blocks the dopamine transporter, leading to increased concentrations of dopamine in the striatum ${ }^{46}$. Thus, we assessed the effect of exposure to methylphenidate $\left(3 \mathrm{mg} \mathrm{kg}^{-1}\right.$, intraperitoneal (i.p.)) $1 \mathrm{~h}$ before each extinction session on reinstatement (cocaine priming) and spontaneous recovery. The main finding was that, similar to cocaine, exposure to methylphenidate accelerated extinction responding, and decreased reinstatement (cocaine priming) and spontaneous recovery (Figs 7-8).
In Experiment 12 (Fig. 7), the statistical analysis, which included the between-subjects factor of Group and the withinsubjects factor of Cocaine priming $\left(0,5,10\right.$ and $\left.15 \mathrm{mg} \mathrm{kg}^{-1}\right)$, showed main effects of Cocaine Priming $\left(F_{(3,48)}=11.4, P<0.01\right)$ and Group $\left(F_{(1,16)}=24.0, P<0.01\right)$. No group differences were found for responding on the inactive nose-poke operandum $(P$ values $>0.1)$. In addition, methylphenidate injections accelerated extinction responding $\left(F_{(13,208)}=2.3, P<0.01\right.$ for Group $\times$ Extinction Session).

In Experiment 13 (Fig. 8), the statistical analysis, which included the between-subjects factor of Group and the withinsubjects factor of Test condition (immediate extinction session, delay 28-day extinction session), showed an interaction between the two factors $\left(F_{(1,16)}=7.8, P<0.05\right)$. No group differences were found for responding on the inactive nose-poke operandum $(P$ values $>0.1)$. In addition, methylphenidate injections accelerated extinction responding $\left(F_{(13,208)}=24.3, P<0.01\right.$ for the effect of Extinction Session; $F_{(1,16)}=4.9, P<0.05$ for group effect).

\section{Discussion}

We developed a UCS memory retrieval-extinction procedure and compared its effects on relapse with the CS memory retrievalextinction procedure ${ }^{13}$. When the memory retrieval-extinction manipulations started 1 day after cocaine self-administration, 


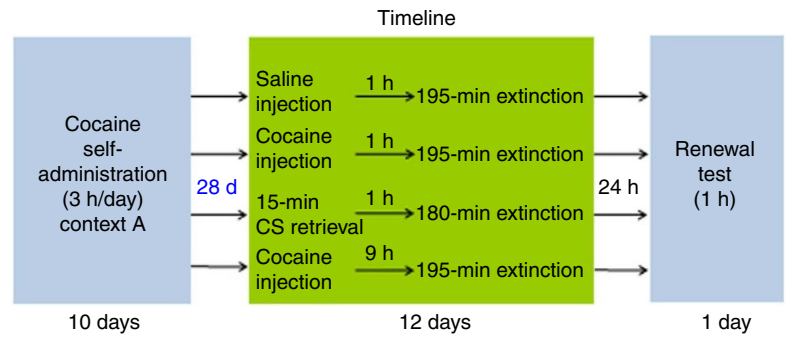

b

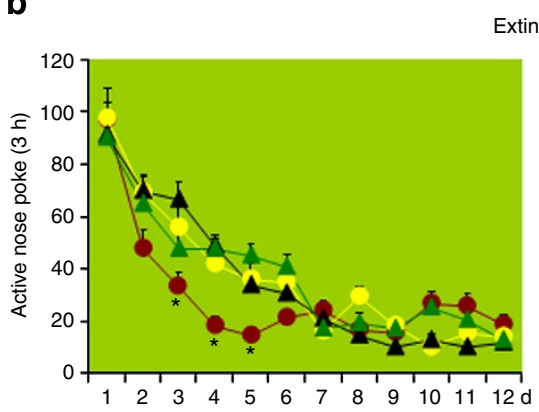

Extinction training

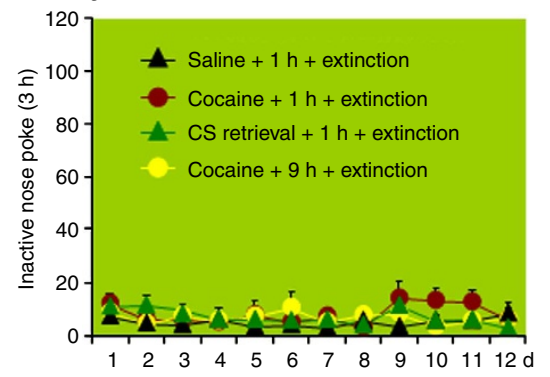

C

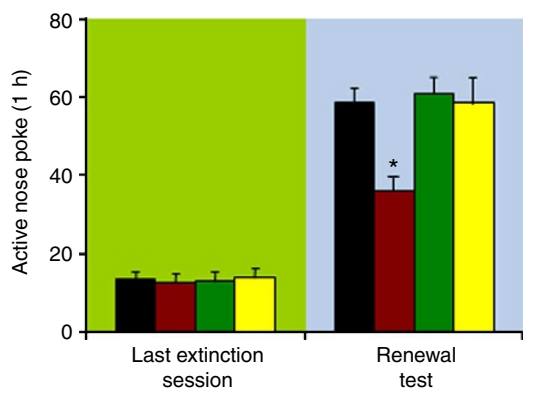

Renewal test

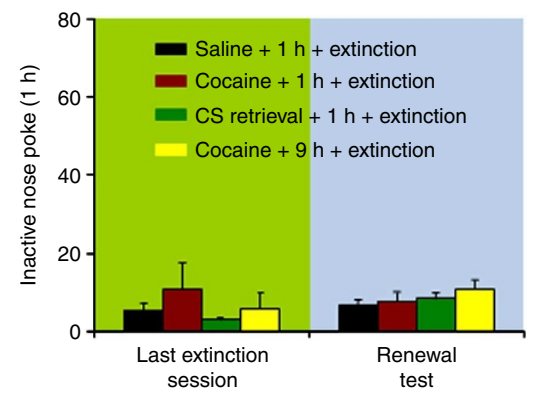

Figure 4 | Exposure to the UCS but not to the CS memory retrieval-extinction manipulation 28 days after cocaine self-administration training accelerated extinction responding and decreased renewal of cocaine seeking. (a) Timeline of the experimental procedure. (b,c) The mean number of responses on the active and inactive nose-poke devices during the extinction phase and renewal test. *Different from 'saline $+1 \mathrm{~h}+$ extinction', mixed ANOVA, ${ }^{\star} P<0.05 ; n=11-12$ per experimental condition. Error bars represent s.e.m.

both procedures decreased reinstatement (cocaine priming), spontaneous recovery, and renewal (context-induced reinstatement) of cocaine seeking. The UCS retrieval manipulation and, to a lesser degree, the CS retrieval manipulation also decreased the reacquisition of cocaine self-administration. However, when we imposed a 28-day withdrawal period before starting the UCS or CS memory retrieval-extinction procedures, the UCS retrieval manipulation effectively decreased reinstatement, spontaneous recovery and renewal, while the CS retrieval manipulation did not. In addition, the UCS but not CS retrieval manipulation decreased reinstatement and renewal of cocaine seeking in the presence of discrete drug-associated cues that were not previously extinguished during extinction training. Importantly, the inhibitory effect of the UCS memory retrieval manipulation on relapse to cocaine seeking was also observed with methylphenidate, an FDA-approved drug for the treatment of attention-deficit hyperactivity disorder (ADHD). We also found that prior exposure to both the CS and UCS memory retrieval procedures decreased neuronal activation in ACC, BLA and NAc core and shell during the spontaneous recovery and renewal tests. More importantly, our data indicate that endocytosis of AMPAR in BLA plays a critical role in the inhibitory effect of UCS memory retrieval-extinction procedure on reinstatement of cocaine seeking.
Our rationale for the development of the UCS memory retrieval-extinction procedure was based on several recent findings from fear conditioning and drug addiction studies demonstrating potential limitations of the CS memory retrievalextinction procedure ${ }^{17,47}$. These include selectivity of the inhibitory effect of the CS retrieval manipulation to fear ${ }^{11,12}$ - or drug (present study)-reactivated cues, which does not generalize to other fear or drug cues that were not reactivated. In addition, inhibition of fear or cocaine seeking only occurs when the CS retrieval-extinction manipulation is performed immediately after fear conditioning ${ }^{10,48}$ or cocaine self-administration (present study) training. Furthermore, for both alcohol self-administration and morphine CPP, the procedure accelerates reacquisition ${ }^{15,16}$; however, we did not replicate these previous findings for cocaine self-administration in the present study. These different results may be because of the use of different animal models (oral alcohol self-administration and morphine CPP versus intravenous cocaine self-administration) and different procedures (extinction in the training context versus extinction in a novel context and assessment of reacquisition using fixed ratio reinforcement schedule versus PR reinforcement schedule).

On the basis of the above limitations of the CS retrieval manipulation, and results demonstrating the inhibitory effects of neuropharmacological manipulations on both fear conditioning ${ }^{18}$ 
a

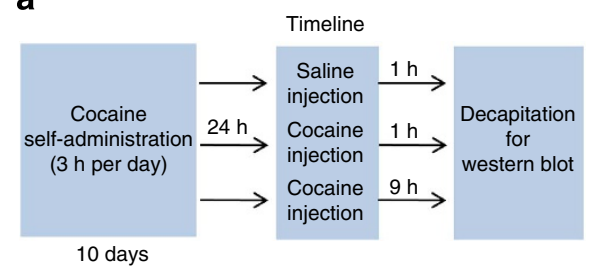

b

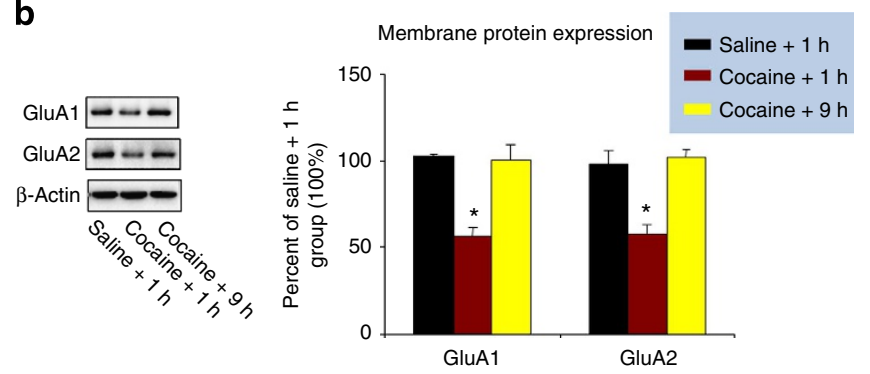

Figure 5 | Exposure to UCS decreased membrane expression of GluA1 and GluA2 in BLA. (a) Timeline of the experimental procedure.

(b) Membrane expression of GluA1 and GluA2 proteins after the different experiment manipulations. Values are the mean percentage of protein levels in the BLA in reference to the saline $+1 \mathrm{~h}+$ extinction group. One-way ANOVA, *Different from group 'saline $+1 \mathrm{~h}+$ extinction', ${ }^{\star} P<0.05 ; n=6$ per experimental condition. Error bars represent s.e.m. Uncropped western blots of the data depicted in Fig. 5 are provided in Supplementary Fig. 10.

and morphine or cocaine $\mathrm{CPP}^{19,20}$ after memory retrieval was induced by the UCS (footshock or drug), we have developed the present UCS memory retrieval-extinction procedure. Our results indicate that the range of conditions under which cocaine seeking is inhibited by this procedure was larger than those under which the inhibitory effects of the CS memory retrieval-extinction procedure are observed. Specifically, unlike the CS retrieval manipulation, the UCS retrieval manipulation decreased renewal and reinstatement of cocaine seeking in the presence of cues that were not present during extinction training, and also inhibited cocaine seeking when the procedure started after 28 withdrawal days. In addition, the UCS retrieval manipulation was somewhat more effective than the CS retrieval manipulation in decreasing reacquisition of cocaine self-administration (Supplementary Fig. 8).

The development of the CS memory retrieval-extinction procedure for both fear conditioning ${ }^{9,11}$ and drug relapse ${ }^{13}$ was on the basis of theoretical accounts of memory retrieval and reconsolidation and studies on the effects of neuropharmacological manipulations (for example, inhibition of protein synthesis) on reconsolidation of appetitive and aversive memories $34,35,49$. Reconsolidation refers to a process wherein memories are maintained after their retrieval and destabilization (destabilization refers to the return of a memory to a labile phase after memory retrieval $)^{47,49}$. Investigators have inferred that memory reconsolidation was disrupted when post-retrieval neuropharmacological manipulations within a specific time interval (up to $2 \mathrm{~h}$ post retrieval, a 'reconsolidation window') disrupt the expression of the conditioned responses $33,35,50$.

Within this framework, and the finding that inhibition of protein synthesis in BLA after UCS (shock) retrieval prevented conditioned fear ${ }^{18}$, the finding that our UCS retrieval manipulation decreased reinstatement, spontaneous recovery, and renewal when rats were exposed to non-contingent cocaine injections $1 \mathrm{~h}$ but not $9 \mathrm{~h}$ before the extinction sessions supports a reconsolidation interpretation of our data. Additional support for the reconsolidation interpretation is that reversal of the experimental conditions-extinction sessions before cocaine UCS exposure-had no effect on renewal of cocaine seeking.

However, a reconsolidation account of our data should be made with caution. First, in most experiments (see figures), nosepoke responding was significantly lower during the last extinction session than during the reinstatement, spontaneous recovery, and renewal tests. Furthermore, the effect of the UCS retrieval manipulation on extinction responding-a behaviour induced by exposure to drug-associated cues ${ }^{51}$-was modest and somewhat inconsistent across experiments (see figures). Therefore, as with the CS retrieval manipulation (present results and ref. 13), the UCS retrieval manipulation only weakened cocaine cue memories (or alternatively decreased the motivational effects of the cues) rather than completely preventing the expression of the conditioned response, as would have been predicted by a reconsolidation account of the data.

One alternative interpretation is that UCS (cocaine) exposure within the consolidation window of extinction memory has strengthened this memory, rendering the original appetitive memory less susceptible to reinstatement, spontaneous recovery, or renewal. In this regard, pharmacological manipulations that promote consolidation of extinction memory decrease reinstatement, spontaneous recovery, and renewal of conditioned fear ${ }^{52,53}$. However, an enhancement of extinction consolidation account of our data is somewhat unlikely because cocaine (UCS) exposure $1 \mathrm{~h}$ after extinction training (within a putative extinction consolidation window) had no effect on renewal of cocaine seeking.

Another alternative interpretation of the data is that the UCS retrieval manipulation decreased non-reinforced cocaine seeking because repeated non-contingent cocaine exposure before the extinction sessions facilitates discrimination between reinforced and non-reinforced sessions. This notion is based on the account that $\mathrm{McNally}$ and colleagues ${ }^{16}$ provided for the mechanism underlying the CS retrieval manipulation to explain their findings that this procedure inhibited renewal of alcohol seeking, but unexpectedly increased reacquisition of alcohol selfadministration. However, it is unlikely that the improved discrimination' hypothesis can explain our data because we found that the UCS retrieval manipulation decreased both nonreinforced cocaine seeking during the relapse tests and reacquisition of cocaine self-administration.

Mihindou et al. ${ }^{54}$ reported that the effect of cocaine priming $\left(15 \mathrm{mg} \mathrm{kg}^{-1}\right)$ on reinstatement after extinction is decreased over repeated testing in the drug context, an effect that is contextdependent. These results may suggest that the inhibitory effect of the UCS retrieval manipulation is merely due to extinction of the response to cocaine priming. This possibility is unlikely for two reasons. First, cocaine has a short half-life in rats $(30 \mathrm{~min})^{55}$; thus, it is unlikely that extinction training performed $1 \mathrm{~h}$ after injections of a low cocaine dose $\left(3 \mathrm{mg} \mathrm{kg}^{-1}\right.$, i.p) was in the presence of pharmacologically relevant doses of cocaine. Second, unlike the finding of Mihindou et al. ${ }^{54}$ on the context-dependent effect of their cocaine-priming manipulation, the inhibitory effect of the UCS retrieval manipulation for cocaine priming was context-independent (Fig. 1).

Finally, an important question is the brain mechanisms underlying the inhibitory effect of the UCS retrieval manipulation on cocaine seeking. Our c-Fos data (Supplementary Figs 3 and 6) suggest a role of ACC, BLA, and NAc; brain areas involved in relapse to drug seeking 37,38 and conditioned drug effects ${ }^{40}$. However, from a mechanistic perspective these correlational data should be interpreted with caution because it is unknown whether increased c-Fos expression is the cause or the consequence of the rats' behaviour in the relapse tests. Our data from subsequent experiments, however, demonstrate an important role of AMPAR 
a

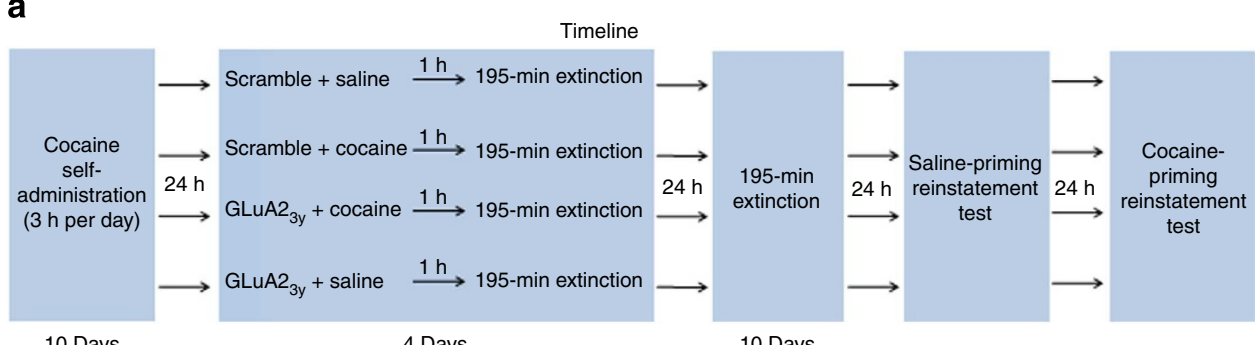

10 Days 4 Days 10 Days

b

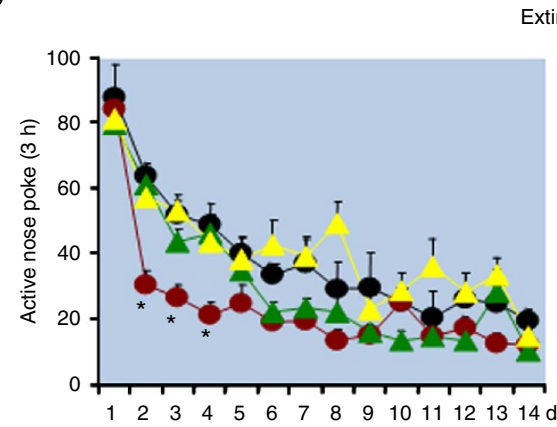

Extinction training

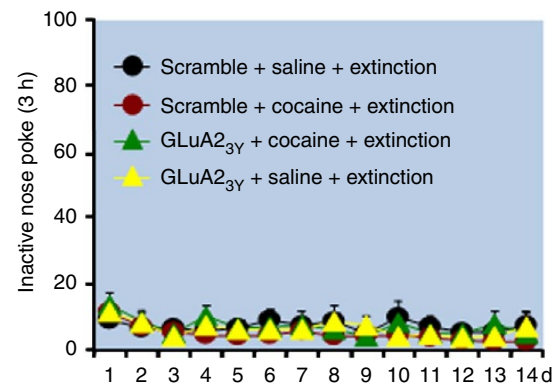

C

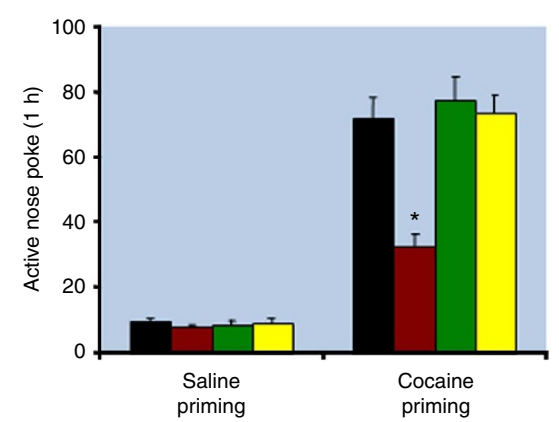

Cocaine-priming test

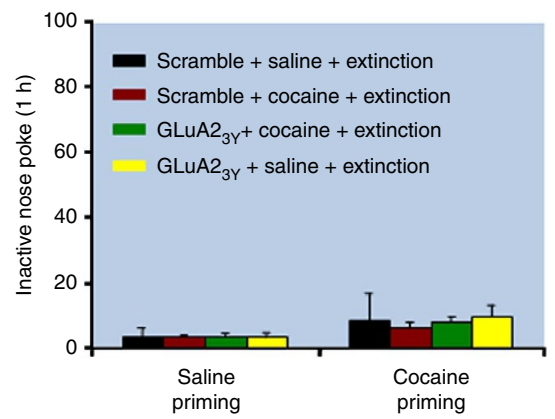

Figure 6 | Blockade of endocytosis of AMPAR in BLA inhibits the effect of UCS memory retrieval-extinction procedure on reinstatement of cocaine seeking. (a) Timeline of the experimental procedure. $(\mathbf{b}, \mathbf{c})$ The mean number of responses on the active and inactive nose-poke devices during the extinction phase and the test for cocaine priming $\left(10 \mathrm{mg} \mathrm{kg}^{-1}\right)$-induced reinstatement of cocaine seeking. *Different from other groups, mixed ANOVA, ${ }^{\star} P<0.05 ; n=9-11$ per experimental condition. Error bars represent s.e.m.

endocytosis in BLA in the inhibitory effect of the UCS retrieval manipulation on reinstatement of cocaine seeking. Thus, noncontingent cocaine injections (the UCS retrieval manipulation) decreased the expression of GluA1 and GluA2 in the membrane fraction of BLA neurons. More importantly, inhibition of endocytosis of AMPAR by BLA injections of GluA2 $2_{3 y}$ (refs 43,44) blocked the effect of the UCS memory retrieval-extinction procedure on reinstatement of cocaine seeking. This mechanistic account of the UCS memory retrieval procedure extends findings from previous studies on the role of AMPAR endocytosis in BLA in memory retrieval and reconsolidation $^{10,23,24}$. However, we cannot exclude that glutamate receptor transmission and synaptic plasticity in other brain regions such as the $\mathrm{NAc} \mathrm{c}^{26,56,57}$ also plays a role in the inhibitory effect of the UCS retrieval manipulation on cocaine seeking.

Finally, in a recent study we reported on the development of a CS memory retrieval-extinction procedure and demonstrated its efficacy in decreasing drug relapse in a rat model and heroin craving in humans ${ }^{13}$. However, as discussed above and demonstrated in the present report, two main limitations of the CS-based retrieval procedure is that it is not effective after prolonged withdrawal periods and its inhibitory effect on relapse is limited to the reactivated CS. Here we showed that the UCS memory retrieval-extinction procedure can overcome these two main limitations of the CS-based procedure and, importantly, that an FDA-approved drug, methylphenidate, can mimic cocaine's effects in the 'improved' UCS-based procedure. We propose that using this procedure in the clinic with methylphenidate or other FDA-approved reuptake blockers of the dopamine transporter could be a promising method for decreasing relapse in cocaine addicts.

\section{Methods}

Subjects. We received male Sprague-Dawley rats, weighing $260-280 \mathrm{~g}$, from the Laboratory Animal Center, Peking University Health Science Center. We housed the rats in groups of five in a temperature- $\left(23 \pm 2{ }^{\circ} \mathrm{C}\right)$ and humidity $(50 \pm 5 \%)$ controlled animal facility with free access to food and water and kept them on a reverse 12-h/12-h light/dark cycle. We performed the experimental procedures in accordance with the National Institutes of Health Guide for the Care and Use of Laboratory Animals and the procedures were approved by the Biomedical Ethics Committee for animal use and protection of Peking University.

Surgery (Experiments 1-13). We anaesthetized the rats (weighing 300-320 g when surgery began) with sodium pentobarbital anaesthesia $\left(60 \mathrm{mg} \mathrm{kg}^{-1}\right.$, i.p.) and inserted catheters into the right jugular vein with the tip terminating at the opening 
a

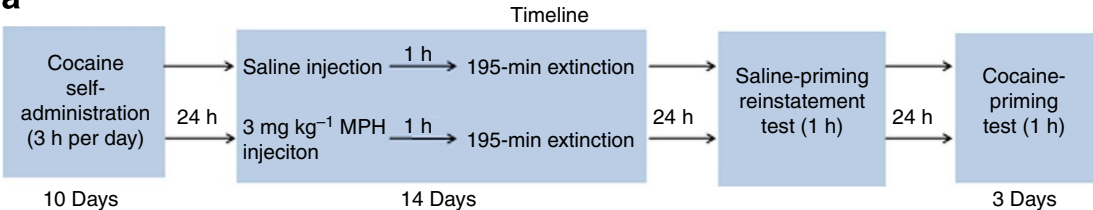

b

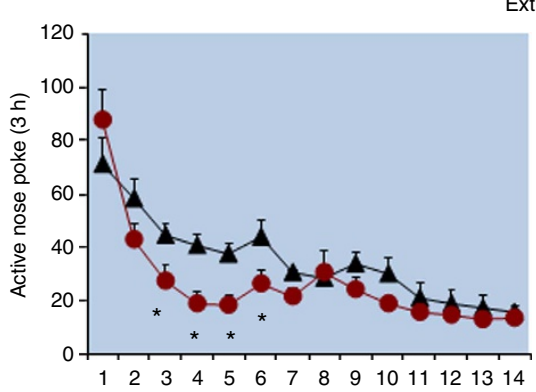

Extinction training

C
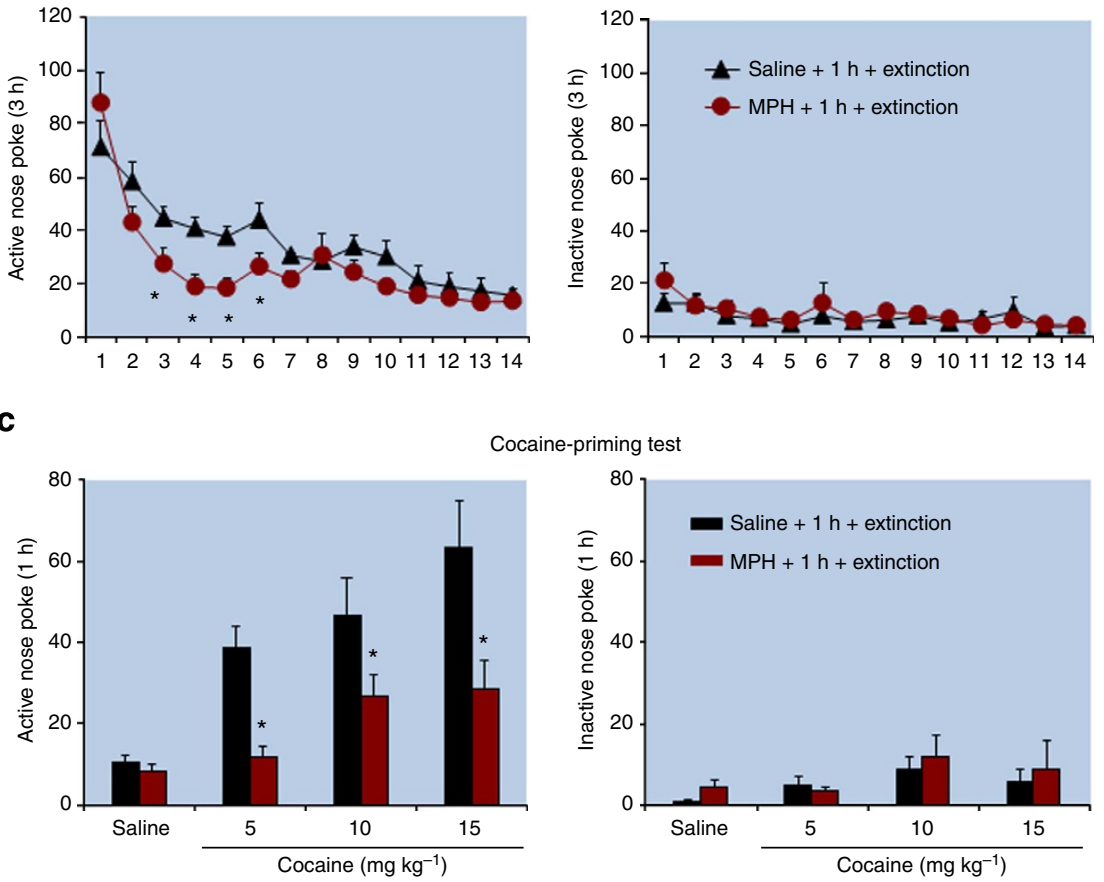

Cocaine-priming test

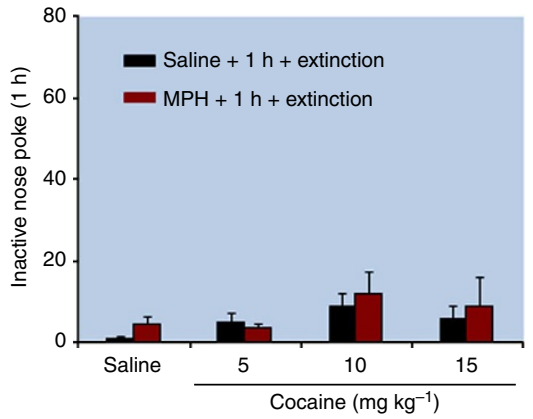

Figure 7 | Exposure to methylphenidate $1 \mathrm{~h}$ before extinction training accelerated extinction responding and decreased reinstatement of cocaine seeking. (a) Timeline of the experimental procedure. $(\mathbf{b}, \mathbf{c})$ The mean number of responses on the active and inactive nose-poke devices during the extinction phase and the reinstatement test. ${ }^{\star}$ Different from 'saline $+1 \mathrm{~h}+$ extinction', mixed ANOVA, ${ }^{\star} P<0.05 ; n=9$ per experimental condition. Error bars represent s.e.m. MPH, methylphenidate.

of the right atrium as previously described ${ }^{13,58}$. We allowed the rats to recover for 5-7 days after surgery.

We implanted 23-gauge guide cannulas (Plastics One) $1 \mathrm{~mm}$ above the BLA. The coordinates for the BLA were anterior/posterior $-2.9 \mathrm{~mm}$, medial/ lateral $\pm 5.0 \mathrm{~mm}$, dorsal/ventral $-8.5 \mathrm{~mm}$ (refs 59,60; Supplementary Fig. 11). We anchored the cannulas to the skull with stainless steel screws and dental cement. We inserted a stainless steel blocker into each cannula to maintain patency and prevent infection.

Intravenous cocaine self-administration training (Experiments 1-13). The chambers (AniLab Software \& Instruments) were equipped with two nose-poke operandi (AniLab Software \& Instruments) located $5 \mathrm{~cm}$ above the floor of the chambers. Nose pokes in one (active) operandum led to cocaine infusions that were accompanied by a 5 -s tone-light cue. Nose pokes in the other (inactive) operandum were also recorded but had no consequence. We trained rats to self-administer cocaine hydrochloride $\left(0.75 \mathrm{mg} \mathrm{kg}^{-1}\right.$ per infusion) during three 1-h daily sessions (separated by $5 \mathrm{~min}$ ) over 10 days. The sessions began at the onset of the dark cycle. We used an FR1 reinforcement schedule with a 40-s timeout period after each infusion. For reacquisition of cocaine self-administration, we used a progressiveratio reinforcement schedule in which the requirements after each reward delivery were increased in the following way: 1, 2, 4, 6, 9, 12, 15, 20 and so on, as described previously ${ }^{41}$.

Each session began with the illumination of a house light that remained on for the entire session. We limited the number of cocaine infusions to $20 \mathrm{~h}^{-1}$ to prevent overdose. At the end of the training phase, we matched the groups in the different experimental conditions for their cocaine intake during training. We used these training conditions on the basis of our previous study ${ }^{13}$.

Retrieval trials induced by UCS or CS. UCS retrieval manipulation: We injected the rats non-contingently with saline $(0.5 \mathrm{ml}$, i.p.) or the previously self-administered drug (UC; cocaine ( 3 or $10 \mathrm{mg} \mathrm{kg}^{-1}$, i.p.)) in their home cage at different time points before the start of the 12- to 14-daily 195-min extinction sessions. We based the cocaine UCS retrieval doses on previous studies using the reinstatement procedure ${ }^{51,61}$; these studies also guided our choice for the cocaine-priming doses during the reinstatement tests described below.

CS retrieval manipulation: This manipulation was identical to the one used in our previous study ${ }^{13}$. We gave the rats short $(15 \mathrm{~min})$ daily sessions during which nose-poke responding led to contingent delivery of the 5-s tone-light cue but not cocaine. We started the 180-min daily extinction sessions $1 \mathrm{~h}$ after the CS retrieval manipulation.

Extinction of drug-reinforced responding. During the extinction sessions ( $195 \mathrm{~min}$ for the UCS retrieval condition and $180 \mathrm{~min}$ for the CS retrieval condition), the conditions were the same as during training, except that active nose-poke response resulted in the delivery of the tone-light cue, but not cocaine infusions. We gave the rats 12-14 daily extinction sessions.

Test for reinstatement of drug seeking. The test conditions were the same as during training (and the CS retrieval manipulation, except for Experiment 5), with the exception that active nose pokes were not reinforced by cocaine. Each session began with illumination of the house light, which remained on for the entire session. Nose-poke responding during the test sessions resulted in contingent presentations of the tone-light cue that had previously been paired with drug infusions but not cocaine. During the drug-priming reinstatement tests, we injected cocaine $5 \mathrm{~min}$ before the start of the sessions.

Immunohistochemistry. We performed immunohistochemistry for c-Fos in brain tissue sections according to previous studies with minor modifications ${ }^{62,63}$. Thirty minutes after the behavioural tests, we perfused six randomly chosen rats per group with $4 \%$ paraformaldehyde, removed the brains and post-fixed them for $24 \mathrm{~h}$. We then sectioned the brains $(30-\mu$ coronal sections) with a microtome. We collected every third serial section on gelatin-coated microscope slides. We then placed the sections in freshly prepared methanol- $\mathrm{H}_{2} \mathrm{O}_{2}$ solution for 10 min to block endogenous peroxidase activity. After incubation with rabbit anti-Fos (sc-52, Lot \#J2313, Santa Cruz Biotechnology; 1:200 dilution in PBS, overnight at $4^{\circ} \mathrm{C}$, then $30 \mathrm{~min}$ at $37^{\circ} \mathrm{C}$ ), the tissue sections were washed three times in PBS, followed by 
a

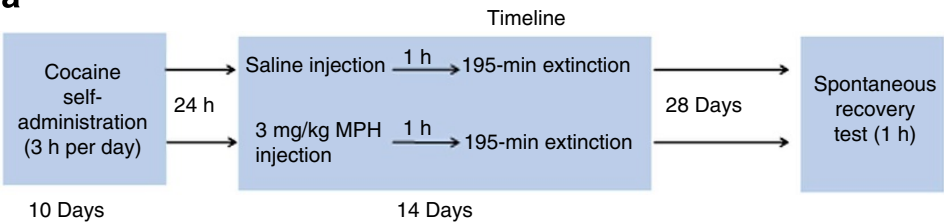

b

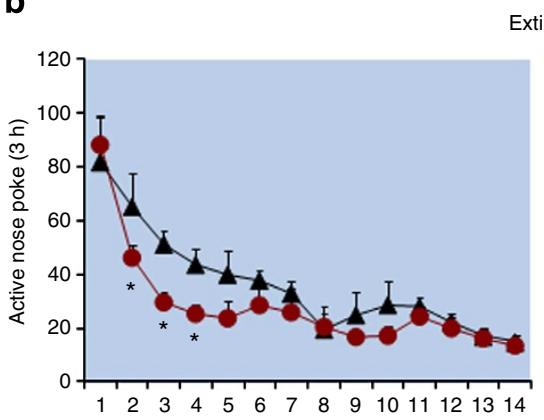

Extinction training

C
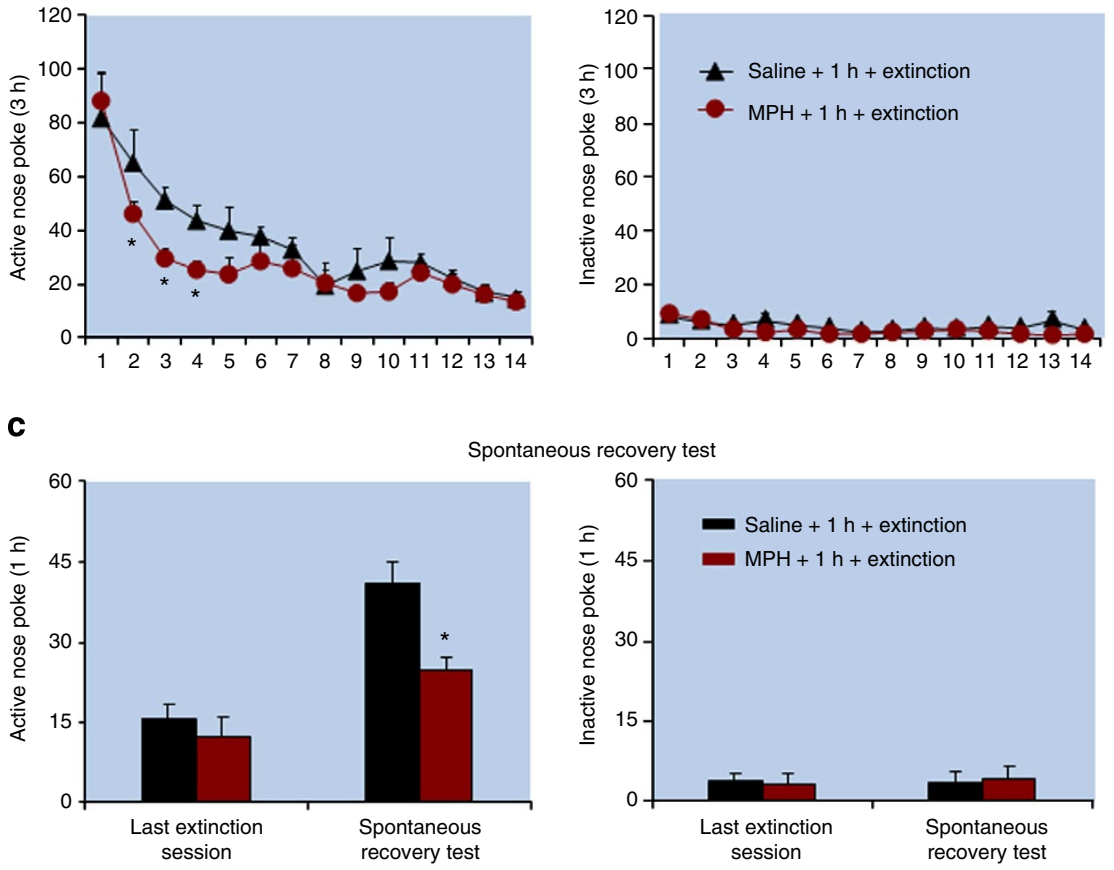

Figure 8 | Exposure to methylphenidate $1 \mathrm{~h}$ before extinction training accelerated extinction responding and decreased spontaneous recovery of cocaine seeking. (a) Timeline of the experimental procedure. $(\mathbf{b}, \mathbf{c})$ The mean number of responses on the active and inactive nose-poke devices during the extinction phase and spontaneous recovery test. ${ }^{\star}$ Different from 'saline $+1 \mathrm{~h}+$ extinction', mixed ANOVA, ${ }^{\star} P<0.05 ; n=9$ per experimental condition. Error bars represent s.e.m. MPH, methylphenidate.

additional $1 \mathrm{~h}$ incubation with biotin-conjugated second antibody and three washes with PBS. We then incubated the sections for $10 \mathrm{~min}$ in streptavidin peroxidase and washed them three times in PBS. Next, we reacted the sections with a $0.05 \%$ solution of 3,30-diaminobenzidine (DAB, Beijing Zhongshan Golden-Bridge Biological Technology) and $0.01 \% \mathrm{H}_{2} \mathrm{O}_{2}$ in $0.1-\mathrm{M}$ PBS. Incubation times varied from 3 to $10 \mathrm{~min}$, depending on the expression levels of the DAB reaction product determined using microscopy.

To exclude the possibility that different developmental procedures across treatment groups would confound the Fos comparisons we incubated sections from a given brain area from the different groups for an equal time. We assessed Fos protein expression in the ACC, PrL, IL, CeA, BLA, and NAc core and shell. The number of Fos-positive cells in these brain regions was counted according to previous studies from our laboratory ${ }^{64,65}$, in which two or three sections from each brain region for each rat were selected. The cell numbers on either side of a given brain region were averaged and taken as the positive immunoreactive cell number for each rat. We measured the number of Fos-labelled cells using a cast-grid microscope (MetaMorph/DP10/Bx41, UIC/Olympus, US/JP) with an imageanalysis programme (MetaMorph, version 4.65).

Intracranial injections. We injected Tat-GluA2 $2_{3 \mathrm{Y}}(45 \mathrm{pmol}$ per side) and Scrambled Tat-GluA2 $2_{3 Y}$ ( 45 pmol per side) bilaterally into BLA with Hamilton syringes connected to 30-gauge injectors (Plastics One). We based the dose of the peptides on previous reports ${ }^{44,66}$. We injected a total volume of $0.5 \mu$ l bilaterally over $1 \mathrm{~min}$ and kept the injector in place for an additional $1 \mathrm{~min}$ to allow for diffusion. At the end of the experiments, we anaesthetized the rats with sodium pentobarbital $\left(100 \mathrm{mg} \mathrm{kg}^{-1}\right.$, i.p.) and transcardially perfused them. We verified cannula placements using Nissl staining with a section thickness of $40 \mu \mathrm{m}$ under light microscopy. We excluded three rats with misplaced cannulas from the statistical analysis.

Western blot assays. We based the assay's procedures on those used in our previous studies ${ }^{21,67,68}$. After decapitation, we rapidly extracted the rats' brains, froze them in $-60^{\circ} \mathrm{C} \mathrm{N}$-hexane and then transferred the brains to $-80^{\circ} \mathrm{C}$ freezer. We placed bilateral tissue punches (12 gauge) of the BLA in a $1.5-\mathrm{ml}$ microtube that contained ice-cold homogenization buffer $(0.32 \mathrm{M}$ sucrose, $4 \mathrm{mM}$ HEPES, $1 \mathrm{mM}$ EDTA, $1 \mathrm{mM}$ EGTA and protease/phosphatase inhibitor cocktail, $\mathrm{pH}$ 7.4). After homogenizing the sample by an electrical disperser (Wiggenhauser, $\mathrm{Sdn}$ Bhd), we centrifuge the homogenate at $1,000 \mathrm{~g}$ for $10 \mathrm{~min}$ at $4{ }^{\circ} \mathrm{C}$ to obtain the pellet (P1) that contained nuclei and large debris. We centrifuged again the supernatant (S1) at $10,000 \mathrm{~g}$ for $30 \mathrm{~min}$ at $4{ }^{\circ} \mathrm{C}$ to generate a crude synaptosomal fraction (P2) and supernatant (S2; the cytosolic fraction). We lysed the crude synaptosomal membrane pellet (P2) hypo-osmotically and centrifuged it at 25,000g for $30 \mathrm{~min}$ at $4{ }^{\circ} \mathrm{C}$ to generate the synaptosomal membrane fraction (LP1). The S2 and LP1 were separately resuspended in HEPES-lysis buffer (50 mM HEPES, $1 \mathrm{mM}$ EDTA, $1 \mathrm{mM}$ EGTA and protease/phosphatase inhibitor cocktail, pH 7.4). We determined the protein concentrations of all of the samples (S2 and LP1) using the bicinchoninic acid assay (Beyotime Biotechnology).

We further diluted the samples in HEPES-lysis buffer to equalize the protein concentrations. We added $4 \times$ loading buffer (16\% glycerol, $20 \%$-mercaptoethanol, $2 \%$ SDS and $0.05 \%$ bromophenol blue) was added to each sample $(3: 1$, sample:loading buffer) before boiling for $3 \mathrm{~min}$. We cooled the samples and subjected them to SDS-polyacrylamide gel electrophoresis ( $10 \%$ acrylamide/ $0.27 \%$ $\mathrm{N}, \mathrm{N}^{\prime}$-methylenebisacryalamide resolving gel) for $\sim 40 \mathrm{~min}$ at $80 \mathrm{~V}$ in stacking gel and $\sim 1 \mathrm{~h}$ at $130 \mathrm{~V}$ in resolving gel. For each electrophoresis run, increasing amounts of protein pooled from the brain region being tested were used to produce a standard curve. We transferred the proteins electrophoretically to Immobilon-P transfer membranes (Millipore) at $0.25 \mathrm{~A}$ for $2.5 \mathrm{~h}$. We washed the membranes with TBST (Tris-Buffered Saline plus $0.05 \%$ Tween-20, $\mathrm{pH} 7.4$ ) and then placed them in blocking buffer ( $5 \%$ bovine serum albumin (BSA in TBST) overnight at $4{ }^{\circ} \mathrm{C}$.

We then incubated the membranes for $1 \mathrm{~h}$ at room temperature on an orbital shaker with anti-GluR1 (ab109450, 1:1,000; Abcam), anti-GluR2 (ab52932, 1:1,000; Abcam) or $\beta$-actin (sc-47778, 1:1,000; Santa Cruz) in TBST plus 5\% BSA and $0.05 \%$ sodium azide. After three 5 -min washes in TBST buffer, we incubated the blots for $45 \mathrm{~min}$ at room temperature on a shaker with horseradish peroxidaseconjugated secondary antibody (goat anti-rabbit IgG; Santa Cruz; PI-1,000; Vector 
Labs) diluted 1:5,000 in blocking buffer. We then washed the blots three times for $5 \mathrm{~min}$ each in TBST and incubated with a layer of Super Signal Enhanced chemiluminescence substrate (Detection Reagents 1 and 2, 1:1 ratio, Pierce Biotechnology) for $1 \mathrm{~min}$ at room temperature. We removed excess mixture before the wrapping the blots with a clean piece of plastic wrap (no bubbles between blot and wrap) and detected the blots by ChemiDoc MP (Bio-Rad). We quantified band intensities using two observers who were blind to the experimental groups using the Quantity One software (version 4.4.0, Bio-Rad). We compared band intensities from each test sample to the band intensities from the standard curves. The amount of the protein of interest in each sample was interpolated from the standard curve. The standard curve runs in all western blots in our studies demonstrate that the band intensities for each of our test samples were within the linear range of detection.

Specific experiments. Experiment 1: Effect of UCS and CS retrieval manipulations on cocaine-priming-induced reinstatement: We trained rats to self-administer intravenous cocaine during three 1-h daily sessions over 10 days. After training, we divided the rats into five experimental groups: saline injections $1 \mathrm{~h}$ before the extinction sessions, cocaine $\left(3 \mathrm{mg} \mathrm{kg}^{-1}\right) 1$ or $9 \mathrm{~h}$ before the extinction sessions, cocaine $\left(10 \mathrm{mg} \mathrm{kg}^{-1}\right) 1 \mathrm{~h}$ before the extinction sessions and 15 -min CS retrieval $1 \mathrm{~h}$ before the extinction sessions. We subsequently tested all rats for reinstatement of nose-poke responding after priming non-contingent injections of saline $(0.5 \mathrm{ml}$, i.p.) and cocaine $\left(5,10\right.$, and $15 \mathrm{mg} \mathrm{kg}^{-1}$, i.p.) in counterbalanced order over 4 days.

Experiment 2: Effect of UCS and CS retrieval manipulations on spontaneous recovery of cocaine seeking: We trained rats to self-administer intravenous cocaine during three 1-h daily sessions over 10 days. After training, we divided the rats into four experimental groups: saline injections $1 \mathrm{~h}$ before the extinction sessions, cocaine $\left(3 \mathrm{mg} \mathrm{kg}^{-1}\right) 1$ or $9 \mathrm{~h}$ before the extinction sessions, and 15-min CS retrieval $1 \mathrm{~h}$ before the extinction sessions. We subsequently tested all rats for spontaneous recovery 28 days after the last extinction session. Thirty minutes after the spontaneous recovery tests, we deeply anaesthetized the rats, perfused them and extracted their brains for subsequent immunohistochemistry assays of Fos.

Experiment 3: Effect of UCS and CS retrieval manipulations on spontaneous recovery of cocaine seeking: We trained rats to self-administer intravenous cocaine during three 1-h daily sessions over 10 days in Context A. After training, we divided the rats into four experimental groups that underwent the UCS and CS retrieval manipulation in Context B: saline injections $1 \mathrm{~h}$ before the extinction sessions, cocaine $\left(3 \mathrm{mg} \mathrm{kg}^{-1}\right) 1$ or $9 \mathrm{~h}$ before the extinction sessions and 15-min CS retrieval $1 \mathrm{~h}$ before the extinction sessions. The experimental procedure is based on previous studies ${ }^{69,70}$, and the two counterbalanced contexts differed from each other as follows: context A had smooth stainless steel rod floor and grey walls; context B had granular flat floor and wallpaper with black and white stripes covered walls. Subsequently, we tested all rats for context-induced reinstatement (renewal) of cocaine seeking in Context A. Thirty minutes after the renewal tests we deeply anaesthetized the rats, perfused them and extracted their brains for subsequent immunohistochemistry assays of Fos.

Experiment 4: Effect of the UCS and CS retrieval manipulations on reacquisition of cocaine self-administration: We trained rats to self-administer intravenous cocaine during three 1-h daily sessions over 10 days. After training, we divided the rats into four experimental groups: saline injections $1 \mathrm{~h}$ before the extinction sessions, cocaine $\left(3 \mathrm{mg} \mathrm{kg}^{-1}\right) 1$ or $9 \mathrm{~h}$ before the extinction sessions and 15 -min CS retrieval $1 \mathrm{~h}$ before the extinction sessions. We subsequently tested all rats for reacquisition of cocaine self-administration for $2 \mathrm{~h}$ per day under the $\mathrm{PR}$ schedule (see above). We chose to assess reacquisition using this schedule instead of the FR1 reinforcement schedule because PR schedules are thought to provide a more direct measure of the rewarding effects of a drug than continuous reinforcement schedules $^{41}$.

Experiment 5: Effect of UCS and CS retrieval manipulations on cocaine seeking induced by cocaine cues not present during extinction training: We trained rats to self-administer intravenous cocaine during three 1-h daily sessions. On training days $1,3,5,7,9,11$ and 13 , we paired cocaine infusions with tone-light cue-1 (continuous $5 \mathrm{~s}, \mathrm{CS} 1$ ) in context $\mathrm{A}^{\prime}$; on training days $2,4,6,8,10,12$ and 14 we paired cocaine infusions with tone-light cue-2 (intermittent $5 \mathrm{~s}: 50 \mathrm{~ms} \times 100$ with 50 -ms interval, CS2) in context $\mathrm{B}^{\prime}$. Thus, the same tone-light cue was given either continuously or intermittently. The contexts were the same as described in Experiment 3. After training, we divided the rats into four experimental groups that underwent the UCS or CS retrieval manipulations in context $\mathrm{B}^{\prime}$ : saline injections $1 \mathrm{~h}$ before the extinction sessions, cocaine $\left(3 \mathrm{mg} \mathrm{kg}^{-1}\right) 1$ or $9 \mathrm{~h}$ before the extinction sessions and 15-min CS1 retrieval plus 15-min CS2 retrieval $1 \mathrm{~h}$ before the extinction sessions. During the extinction sessions, active nose poke led to contingent presentation of CS2. We then performed four consecutive tests: renewal (context-induced reinstatement) test in which nose pokes were reinforced by CS1 in context $\mathrm{A}^{\prime}$, saline priming in context $\mathrm{B}^{\prime}$ (a baseline vehicle condition), cocaine priming $\left(10 \mathrm{mg} \mathrm{kg}^{-1}\right)$ in context $\mathrm{B}^{\prime}$ and cocaine priming in context $\mathrm{A}^{\prime}$. During the tests in context $\mathrm{A}^{\prime}$ and context $\mathrm{B}^{\prime}$, nose pokes led to contingent delivery of CS1 and CS2, respectively.

Experiment 6: Effect of UCS and CS retrieval manipulations on cocaine-priminginduced reinstatement after 28 withdrawal days: The experimental procedure for Experiment 6 was identical to that of Experiment 1, except that the retrievalextinction manipulations started 28 days after training. The experiment included four groups: saline injections $1 \mathrm{~h}$ before the extinction sessions, cocaine $\left(3 \mathrm{mg} \mathrm{kg}^{-1}\right) 1$ or $9 \mathrm{~h}$ before the extinction sessions and 15 -min CS retrieval $1 \mathrm{~h}$ before the extinction sessions.

Experiment 7: Effect of UCS and CS retrieval manipulations on spontaneous recovery after 28 withdrawal days: The experimental procedure and groups for Experiment 7 were identical to that of Experiment 2, except that the retrievalextinction manipulations started 28 days after training.

Experiment 8: Effect of UCS and CS retrieval manipulations on renewal after 28 withdrawal days: The experimental procedure and groups for Experiment 8 were identical to that of Experiment 3, except that the retrieval-extinction manipulations started 28 days after training.

Experiment 9: Effect of reversed sequence of the UCS-retrieval and extinction on renewal of cocaine seeking: The experimental procedure for Experiment 9 was identical to that of Experiment 3, except that the UCS retrieval manipulation was given $1 \mathrm{~h}$ after the extinction sessions. The experiment included two groups: saline or cocaine injections $1 \mathrm{~h}$ after the extinction sessions.

Experiment 10: Effect of CS or UCS retrieval on endocytosis of GluA1 and GluA2 in BLA: We trained rats to self-administer intravenous cocaine during three 1-h daily sessions over 10 days. After training, we divided the rats into three experimental groups: saline injections $1 \mathrm{~h}$ before the decapitation and cocaine $\left(3 \mathrm{mg} \mathrm{kg}^{-1}\right) 1$ or $9 \mathrm{~h}$ before the decapitation. We extracted the BLA of the rats for subsequent western blot assays of GluA1 and GluA2.

Experiment 11: Effect of injections of GluA2 $2_{3 y}$ into BLA on the UCS memory retrieval-extinction manipulation: We trained rats to self-administer intravenous cocaine during three 1-h daily sessions over 10 days. After training, we divided the rats into four experimental groups: injections of scramble $\mathrm{GluA} 2_{3 \mathrm{y}}$ into BLA + saline injection $\left(1 \mathrm{ml} \mathrm{kg}^{-1}\right.$, i.p.), injections of scramble $\mathrm{GluA}_{3 \mathrm{y}}$ into BLA followed by cocaine injection ( $3 \mathrm{mg} \mathrm{kg}^{-1}$, i.p.), injections of $\mathrm{GluA}_{3 \mathrm{y}}$ into BLA followed by saline injection (i.p.), and injections of $\mathrm{GluA}_{3 \mathrm{y}}$ into BLA followed by cocaine injection $\left(3 \mathrm{mg} \mathrm{kg}^{-1}\right.$, i.p.). All rats received extinction training after the different manipulations $1 \mathrm{~h}$ later. We subsequently tested all rats for reinstatement of nose-poke responding after priming non-contingent injections of saline $(0.5 \mathrm{ml}$, i.p.) and cocaine $\left(10 \mathrm{mg} \mathrm{kg}^{-1}\right.$, i.p.).

Experiment 12: Effect of exposure to methylphenidate $1 \mathrm{~h}$ before extinction training on reinstatement of cocaine seeking: We trained rats to self-administer intravenous cocaine during three 1-h daily sessions over 10 days. After training, we divided the rats into two experimental groups: saline injections $1 \mathrm{~h}$ before the extinction sessions and methylphenidate $\left(3 \mathrm{mg} \mathrm{kg}^{-1}\right)$ injections $1 \mathrm{~h}$ before the extinction sessions. We subsequently tested all rats for reinstatement of nose-poke responding after priming non-contingent injections of saline $(0.5 \mathrm{ml}$, i.p.) and cocaine $\left(5,10\right.$ and $15 \mathrm{mg} \mathrm{kg}^{-1}$, i.p.) in counterbalanced order over 4 days.

Experiment 13: Effect of exposure to methylphenidate $1 \mathrm{~h}$ before extinction training on spontaneous recovery of cocaine seeking: We trained rats to selfadminister intravenous cocaine during three 1-h daily sessions over 10 days. After training, we divided the rats into two experimental groups: saline injections $1 \mathrm{~h}$ before the extinction sessions and methylphenidate $\left(3 \mathrm{mg} \mathrm{kg}^{-1}\right)$ injections $1 \mathrm{~h}$ before the extinction sessions. We subsequently tested all rats for spontaneous recovery 28 days after the last extinction session.

Statistical analysis. We report the results as mean \pm s.e.m. and analysed the data by analyses of variance (ANOVAs) with the appropriate between- and withinsubjects factors for each experiment (see Results section). We followed up on significant main effects and interactions $(P<0.05$, two-tailed) from the factorial ANOVAs using Turkey's post hoc tests.

\section{References}

1. Childress, A. R., Mclellan, T. A. \& O’Brien, C. P. Role of conditioning factors in the development of drug dependence. Psychiatr. Clin. North Am. 9, 413-425 (1986).

2. Goldberg, S. R. Stimuli associated with drug injections as events that control behavior. Pharmacol. Rev. 27, 325-340 (1976).

3. Stewart, J., de Wit, H. \& Eikelboom, R. Role of unconditioned and conditioned drug effects in the self-administration of opiates and stimulants. Psychol. Rev. 91, 251-268 (1984).

4. Davis, W. M. \& Smith, S. G. Role of conditioned reinforcers in the initiation, maintenance and extinction of drug-seeking behavior. Pavlov. J. Biol. Sci. 11, 222-236 (1976).

5. Marlatt, G. A. Cue exposure and relapse prevention in the treatment of addictive behaviors. Addict. Behav. 15, 395-399 (1990).

6. Conklin, C. A. \& Tiffany, S. T. Applying extinction research and theory to cue-exposure addiction treatments. Addiction 97, 155-167 (2002).

7. Bouton, M. E. Context, ambiguity, and unlearning: Sources of relapse after behavioral extinction. Biol. Psychiatry 52, 976-986 (2002).

8. Todd, T. P., Vurbic, D. \& Bouton, M. E. Behavioral and neurobiological mechanisms of extinction in Pavlovian and instrumental learning. Neurobiol. Learn. Mem. 108, 52-64 (2014).

9. Monfils, M. H., Cowansage, K. K., Klann, E. \& LeDoux, J. E. Extinctionreconsolidation boundaries: key to persistent attenuation of fear memories. Science 324, 951-955 (2009). 
10. Clem, R. L. \& Huganir, R. L. Calcium-permeable AMPA receptor dynamics mediate fear memory erasure. Science 330, 1108-1112 (2010).

11. Schiller, D. et al. Preventing the return of fear in humans using reconsolidation update mechanisms. Nature 463, 49-53 (2010).

12. Schiller, D., Kanen, J. W., Ledoux, J. E., Monfils, M. H. \& Phelps, E. A. Extinction during reconsolidation of threat memory diminishes prefrontal cortex involvement. Proc. Natl Acad. Sci. USA 110, 20040-20045 (2013).

13. Xue, Y. X. et al. A memory retrieval-extinction procedure to prevent drug craving and relapse. Science 336, 241-245 (2012).

14. Ma, X., Zhang, J. J. \& Yu, L. C. Post-retrieval extinction training enhances or hinders the extinction of morphine-induced conditioned place preference in rats dependent on the retrieval-extinction interval. Psychopharmacology (Berl) 221, 19-26 (2012)

15. Sartor, G. C. \& Aston-Jones, G. Post-retrieval extinction attenuates cocaine memories. Neuropsychopharmacology 39, 1059-1065 (2014).

16. Millan, E. Z., Milligan-Saville, J. \& McNally, G. P. Memory retrieval, extinction, and reinstatement of alcohol seeking. Neurobiol. Learn. Mem. 101, 26-32 (2013).

17. Hutton-Bedbrook, K. \& McNally, G. P. The promises and pitfalls of retrievalextinction procedures in preventing relapse to drug seeking. Front. Psychiatry 4 , 14 (2013).

18. Debiec, J., Diaz-Mataix, L., Bush, D. E., Doyere, V. \& Ledoux, J. E. The amygdala encodes specific sensory features of an aversive reinforcer. Nat. Neurosci. 13, 536-537 (2010).

19. Milekic, M. H., Brown, S. D., Castellini, C. \& Alberini, C. M. Persistent disruption of an established morphine conditioned place preference. $J$. Neurosci. 26, 3010-3020 (2006).

20. Valjent, E., Corbille, A. G., Bertran-Gonzalez, J., Herve, D. \& Girault, J. A. Inhibition of ERK pathway or protein synthesis during reexposure to drugs of abuse erases previously learned place preference. Proc. Natl Acad. Sci. USA 103, 2932-2937 (2006).

21. Liu, J. et al. An unconditioned stimulus retrieval extinction procedure to prevent the return of fear memory. Biol. Psychiatry 76, 895-901 (2014).

22. Shaham, Y., Shalev, U., Lu, L., De Wit, H. \& Stewart, J. The reinstatement model of drug relapse: history, methodology and major findings. Psychopharmacology (Berl). 168, 3-20 (2003).

23. Hong, I. et al. AMPA receptor exchange underlies transient memory destabilization on retrieval. Proc. Natl Acad. Sci. USA 110, 8218-8223 (2013).

24. Rao-Ruiz, P. et al. Retrieval-specific endocytosis of GluA2-AMPARs underlies adaptive reconsolidation of contextual fear. Nat. Neurosci. 14, 1302-1308 (2011).

25. Yu, Y. J., Chang, C. H. \& Gean, P. W. AMPA receptor endocytosis in the amygdala is involved in the disrupted reconsolidation of Methamphetamineassociated contextual memory. Neurobiol. Learn. Mem. 103, 72-81 (2013).

26. Conrad, K. L. et al. Formation of accumbens GluR2-lacking AMPA receptors mediates incubation of cocaine craving. Nature 454, 118-121 (2008).

27. Famous, K. R. et al. Phosphorylation-dependent trafficking of GluR2containing AMPA receptors in the nucleus accumbens plays a critical role in the reinstatement of cocaine seeking. J. Neurosci. 28, 11061-11070 (2008).

28. Jian, M. et al. eIF2alpha dephosphorylation in basolateral amygdala mediates reconsolidation of drug memory. J. Neurosci. 34, 10010-10021 (2014).

29. Lee, J. L., Di Ciano, P., Thomas, K. L. \& Everitt, B. J. Disrupting reconsolidation of drug memories reduces cocaine-seeking behavior. Neuron 47, 795-801 (2005).

30. Sanchez, H., Quinn, J. J., Torregrossa, M. M. \& Taylor, J. R. Reconsolidation of a cocaine-associated stimulus requires amygdalar protein kinase A. J. Neurosci. 30, 4401-4407 (2010).

31. Crombag, H., Bossert, J. M., Koya, E. \& Shaham, Y. Context-induced relapse to drug seeking: a review. Trans. R Soc. Lond. B Biol. Sci. 363, 3233-3243 (2008).

32. McGaugh, J. L. Memory--a century of consolidation. Science 287, 248-251 (2000).

33. Milton, A. L. \& Everitt, B. J. The psychological and neurochemical mechanisms of drug memory reconsolidation: implications for the treatment of addiction. Eur. J. Neurosci. 31, 2308-2319 (2010).

34. Tronson, N. C. \& Taylor, J. R. Molecular mechanisms of memory reconsolidation. Nat. Rev. Neurosci. 8, 262-275 (2007).

35. Nader, K., Schafe, G. E. \& Le Doux, J. E. Fear memories require protein synthesis in the amygdala for reconsolidation after retrieval. Nature 406, $722-726$ (2000)

36. Morgan, J. I. \& Curran, T. Stimulus-transcription coupling in the nervous system: involvement of the inducible proto-oncogenes fos and jun. Annu. Rev. Neurosci. 14, 421-451 (1991).

37. Bossert, J. M., Marchant, N. J., Calu, D. J. \& Shaham, Y. The reinstatement model of drug relapse: recent neurobiological findings, emerging research topics, and translational research. Psychopharmacology (Berl) 229, 453-476 (2013).

38. Kalivas, P. W. \& McFarland, K. Brain circuitry and the reinstatement of cocaine-seeking behavior. Psychopharmacology (Berl). 168, 44-56 (2003).
39. Marchant, N. J., Kaganovsky, K., Shaham, Y. \& Bossert, J. M. Role of corticostriatal circuits in context-induced reinstatement of drug seeking. Brain Res. doi:10.1016/j.brainres.2014.09.004 (6 September 2014).

40. Everitt, B. J., Dickinson, A. \& Robbins, T. W. The neuropsychological basis of addictive behaviour. Brain Res. Rev. 36, 129-138 (2001).

41. Richardson, N. R. \& Roberts, D. C. Progressive ratio schedules in drug self-administration studies in rats: a method to evaluate reinforcing efficacy. J. Neurosci. Methods 66, 1-11 (1996).

42. Ahmadian, G. et al. Tyrosine phosphorylation of GluR2 is required for insulinstimulated AMPA receptor endocytosis and LTD. EMBO J. 23, 1040-1050 (2004).

43. Brebner, K. et al. Nucleus accumbens long-term depression and the expression of behavioral sensitization. Science 310, 1340-1343 (2005).

44. Li, Y. Q. et al. Inhibition of PKMzeta in nucleus accumbens core abolishes longterm drug reward memory. J. Neurosci. 31, 5436-5446 (2011).

45. Corp, S. A., Gitlin, M. J. \& Altshuler, L. L. A review of the use of stimulants and stimulant alternatives in treating bipolar depression and major depressive disorder. J. Clin. Psychiatry 75, 1010-1018 (2014).

46. Berridge, C. W. \& Arnsten, A. F. Psychostimulants and motivated behavior: arousal and cognition. Neurosci. Biobehav. Rev. 37, 1976-1984 (2013).

47. Auber, A., Tedesco, V., Jones, C. E., Monfils, M. H. \& Chiamulera, C. Postretrieval extinction as reconsolidation interference: methodological issues or boundary conditions? Psychopharmacology (Berl) 226, 631-647 (2013).

48. Costanzi, M., Cannas, S., Saraulli, D., Rossi-Arnaud, C. \& Cestari, V. Extinction after retrieval: effects on the associative and nonassociative components of remote contextual fear memory. Learn. Mem. 18, 508-518 (2011).

49. Dudai, Y. Reconsolidation: the advantage of being refocused. Curr. Opin. Neurobiol. 16, 174-178 (2006).

50. Alberini, C. M. Mechanisms of memory stabilization: are consolidation and reconsolidation similar or distinct processes? Trends Neurosci. 28, 51-56 (2005).

51. Shalev, U., Grimm, J. W. \& Shaham, Y. Neurobiology of relapse to heroin and cocaine seeking: a review. Pharmacol. Rev. 54, 1-42 (2002).

52. Graham, B. M., Langton, J. M. \& Richardson, R. Pharmacological enhancement of fear reduction: preclinical models. Br. J. Pharmacol. 164, 1230-1247 (2011)

53. Quirk, G. J. \& Mueller, D. Neural mechanisms of extinction learning and retrieval. Neuropsychopharmacology 33, 56-72 (2008).

54. Mihindou, C., Vouillac, C., Koob, G. F. \& Ahmed, S. H. Preclinical validation of a novel cocaine exposure therapy for relapse prevention. Biol. Psychiatry 70, 593-598 (2011).

55. Hurd, Y. L., Kehr, J. \& Ungerstedt, U. In vivo microdialysis as a technique to monitor drug transport: correlation of extracellular cocaine levels and dopamine overflow in the rat brain. J. Neurochem. 51, 1314-1316 (1988).

56. Lee, B. R. et al. Maturation of silent synapses in amygdala-accumbens projection contributes to incubation of cocaine craving. Nat. Neurosci. 16, 1644-1651 (2013).

57. Thomas, M. J., Beurrier, C., Bonci, A. \& Malenka, R. C. Long-term depression in the nucleus accumbens: a neural correlate of behavioral sensitization to cocaine. Nat. Neurosci. 4, 1217-1223 (2001).

58. Wang, X. et al. Nucleus accumbens core mammalian target of rapamycin signaling pathway is critical for cue-induced reinstatement of cocaine seeking in rats. J. Neurosci. 30, 12632-12641 (2010).

59. Li, F. Q. et al. Basolateral amygdala cdk5 activity mediates consolidation and reconsolidation of memories for cocaine cues. J. Neurosci. 30, 10351-10359 (2010).

60. He, Y. Y. et al. PKMzeta maintains drug reward and aversion memory in the basolateral amygdala and extinction memory in the infralimbic cortex. Neuropsychopharmacology 36, 1972-1981 (2011).

61. Schmidt, H. D., Anderson, S. M., Famous, K. R., Kumaresan, V. \& Pierce, R. C. Anatomy and pharmacology of cocaine priming-induced reinstatement of drug seeking. Eur. J. Pharmacol. 526, 65-76 (2005).

62. Dong, J. et al. Congenital iodine deficiency and hypothyroidism impair LTP and decrease C-fos and C-jun expression in rat hippocampus. Neurotoxicology 26, 417-426 (2005).

63. Sundquist, S. J. \& Nisenbaum, L. K. Fast Fos: rapid protocols for single- and double-labeling c-Fos immunohistochemistry in fresh frozen brain sections. J. Neurosci. Methods 141, 9-20 (2005).

64. Jiang, W. G. et al. Chronic unpredictable stress induces a reversible change of PER2 rhythm in the suprachiasmatic nucleus. Brain Res. 1399, 25-32 (2011)

65. Shi, H. S. et al. PI3K/Akt signaling pathway in the basolateral amygdala mediates the rapid antidepressant-like effects of trefoil factor 3. Neuropsychopharmacology 37, 2671-2683 (2012).

66. Migues, P. V. et al. PKMzeta maintains memories by regulating GluR2dependent AMPA receptor trafficking. Nat. Neurosci. 13, 630-634 (2010).

67. Ren, Z. Y. et al. A critical role for protein degradation in the nucleus accumbens core in cocaine reward memory. Neuropsychopharmacology 38, 778-790 (2013)

68. Xue, Y. X. et al. Depletion of perineuronal nets in the amygdala to enhance the erasure of drug memories. J. Neurosci. 34, 6647-6658 (2014). 
69. Bossert, J. M., Liu, S. Y., Lu, L. \& Shaham, Y. A role of ventral tegmental area glutamate in contextual cue-induced relapse to heroin seeking. J. Neurosci. 24, 10726-10730 (2004)

70. Crombag, H. S. \& Shaham, Y. Renewal of drug seeking by contextual cues after prolonged extinction in rats. Behav. Neurosci. 116, 169-173 (2002).

\section{Acknowledgements}

This work was supported in part by the National Basic Research Program of China (no. 2015CB856400 and 2015CB553503) and the Natural Science Foundation of China (no. 31230033, 81221002 and 91432303). The preparation of the manuscript was also supported in part by the Intramural Research Program of NIDA. We thank Robyn St. Laurent, Shi-Qiu Meng and Chen Chen for editorial assistance and Dr Dorit Ron (UCSF) for helpful comments and advice on the Western Blot assays.

\section{Author contributions}

Y.-x.L., Y.-x.X. and L.L. conceived the project. Y.-x.L., Y.-x.X., J.-f.L., H.-s.S., M.J., Y.H., W.-l.Z., P.W. and Z.-b.D. performed the experiments. Y.-x.L., Y.-x.X., Y.-p.B., H.-W. S. and J.S. analysed the data. Y.-x.L., Y.-x.X., Y.S. and L.L. designed the experiments and wrote the paper, with contributions from all of the other authors.

\section{Additional information}

Supplementary Information accompanies this paper at http://www.nature.com/ naturecommunications

Competing financial interests: The authors declare no competing financial interests.

Reprints and permission information is available online at http://npg.nature.com/ reprintsandpermissions/

How to cite this article: Luo, Y.-X. et al. A novel UCS memory retrieval-extinction procedure to inhibit relapse to drug seeking. Nat. Commun. 6:7675 doi: $10.1038 /$ ncomms8675 (2015)

\section{(c) (i)}

This work is licensed under a Creative Commons Attribution 4.0 International License. The images or other third party material in this article are included in the article's Creative Commons license, unless indicated otherwise in the credit line; if the material is not included under the Creative Commons license, users will need to obtain permission from the license holder to reproduce the material. To view a copy of this license, visit http://creativecommons.org/licenses/by/4.0/ 